Final Technical Report

\title{
Materials Solutions for Hydrogen Delivery in Pipelines DE-FG36-05-GO15036
}

\author{
September 2011 \\ Principal Investigator:
}

Secat, Inc. 


\title{
FINAL TECHINCAL REPORT
}

\author{
Project Title: \\ Materials Solutions for Hydrogen Delivery in Pipelines \\ Covering Period: $\quad$ May 2005 through September, 2011 \\ Date of Report: $\quad$ September 30, 2011 \\ Recipient: $\quad$ Secat, Inc., \\ 1505 Bull Lea Road \\ Coldstream Research Campus \\ Lexington, KY 40511 \\ Award Number: \\ DE-FG36-05GO15036 \\ Subcontractors: \\ Oak Ridge National Laboratory \\ University of Illinois \\ Sandia National Laboratory - Livermore \\ Other Partners: \\ Evraz NA - Oregon Steel Mills \\ Schott North America - Regional R \& D \\ Chemical Composite Coatings Int'l, LLC \\ Advanced Technology Corporation \\ Hatch Moss MacDonald \\ Columbia Gas of Kentucky \\ ASME Standards and Technologies LLC \\ DGS Metallurgical Solutions, Inc \\ Reference Metals Company \\ Contact: \\ Todd Boggess, (859) 514-4989, tboggess@secat.net \\ Project Team: $\quad$ Dr. Monterey Gardiner (DOE-HQ), \\ Dr. Steve Pawel (ORNL) \\ DOE-HQ Project Officer: Paul Bakke \\ DOE- Golden - Award Administrator: Tammie Lawler \\ Team Members: \\ G Muralidharan - Oak Ridge National Laboratory \\ John J Koehr - ASME International \\ Dr. Ian Roberson - University of Illinois \\ Dr. Petros Sofronis - University of Illinois \\ Gail Smith - Evraz NA, Oregon Steel Mills \\ Carsten Weinhold - Schott North America - Regional R \& D \\ Paul Fisher - Chemical Composite Coatings Int'l, LLC \\ Dr Fahmy Haggag - Advanced Technology Corporation \\ Gary Sullivan - Columbia Gas of Kentucky \\ Doug Stalheim - DGS Metallurgical Solutions Inc. \\ Steve Jansto - Reference Metals Company
}




\title{
Materials Solutions for Hydrogen Delivery in Pipelines
}

Shridas Ningileri - Secat, Inc.

Doug Stalheim - DGS Metallurgical Solutions, Inc.

September 2011

\author{
Prepared by \\ Secat, Inc. \\ 1505 Bull Lea Road \\ Coldstream Research Campus \\ Lexington, KY 40511 \\ for the \\ US DEPARTMENT OF ENERGY \\ Under Contract DE-FG36-05-G015036
}




\section{Acknowledgements and Disclaimer}

\section{Acknowledgements}

This report is based upon work supported by the U.S. Department of Energy, Energy Efficiency and Renewable Energy, Hydrogen and Fuel Cells Program under Solicitation No. DE-PS36-03GO93007 with award made to Secat, Inc.

Research was sponsored by the U.S. Department of Energy, Office of Energy Efficiency and Renewable Energy, Hydrogen and Fuel Cells Program under award DE-FG36-05-GO15036 to Secat, Inc.

The significant accomplishments of this project would not have been achieved without access to the excellent facilities of Oak Ridge National Laboratory and Sandia National Laboratories - Livermore CA along with the contributions from academic partners University of Illinois and industry partners Evraz NA - Oregon Steel Mills

Schott North America - Regional R \& D, Chemical Composite Coatings Int'1, LLC, Advanced Technology Corporation, Hatch Moss MacDonald, Columbia Gas of Kentucky, ASME Standards and Technologies LLC, DGS Metallurgical Solutions, Inc., and Reference Metals Company. Thanks are due to the team members of Dr. Govindarajan Muralidharan, Dr. Steve Pawel, Shridas Ningileri, Steve Jansto, Doug Stalheim, Carsten Weinhold, John Koehr, Dr. Ian Roberson, Dr. Petros Sofronis, Gail Smith, Paul Fisher, Dr. Fahmy Haggag, and Gary Sullivan. The principal investigators of this project also realize that the significant accomplishments of this endeavor could not have been achieved except through dedicated and excellent contributions of the other project research team members from the Oak Ridge National Laboratory, the Sandia National Laboratory - Livermore and the University of Illinois including Dr. Tim Armstrong, Dr. Brian Someday and Dr. Chris San Marchi

\section{Disclaimer}

This report was prepared as an account of work sponsored by an agency of the United States Government. Neither the United States Government nor any agency thereof, nor any of their employees, makes any warranty, express or implied, or assumes any legal liability or responsibility for the accuracy, completeness, or usefulness of any information, apparatus, product, or process disclosed, or represents that its use would not infringe privately owned rights, trademark, manufacturer, or otherwise, does not necessarily constitute or imply its endorsement, recommendations, or favoring by the United States Government or any agency thereof. The views and opinions of the authors expressed herein do not necessarily state or reflect those of the United States Government or any agency thereof. 


\section{Table of Contents}

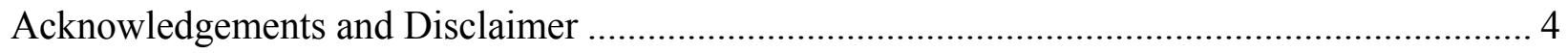

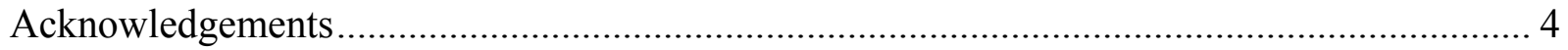

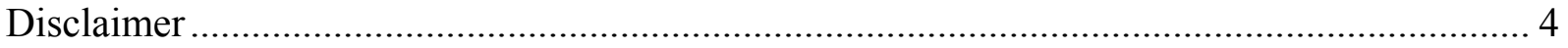

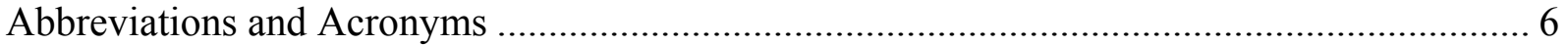

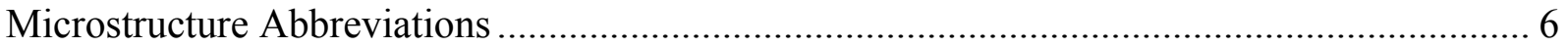

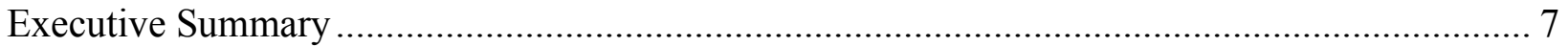

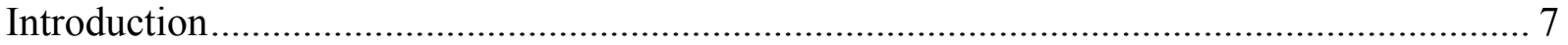

Research and Development..................................................................................... 8

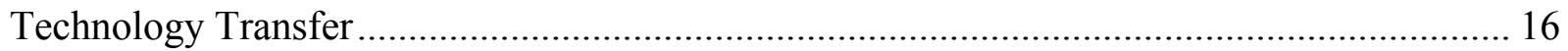

Summary, Conclusions and Recommendations................................................................. 17

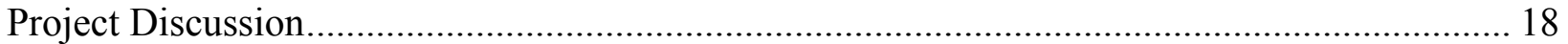

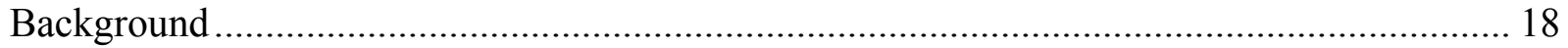

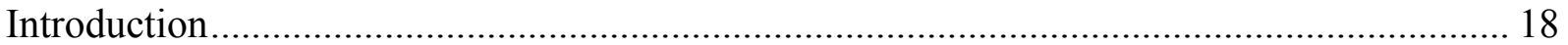

Initial Hydrogen Testing at ATC, ORNL and SNLL …………........................................ 20

Results - As-received Compositions, Mechanical Properties, Expected Microstructure and

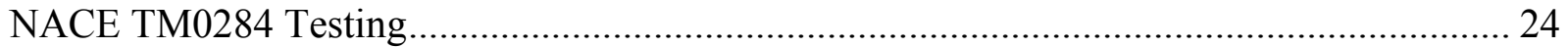

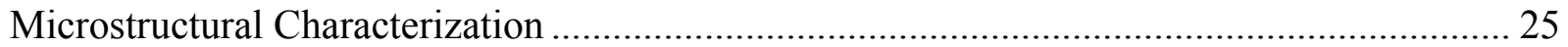

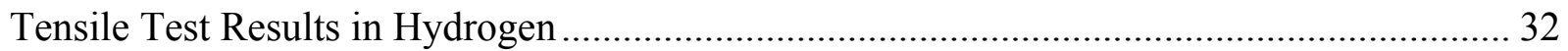

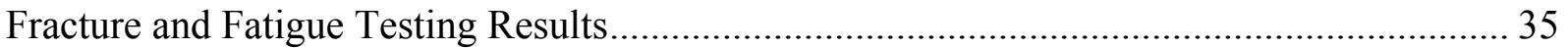

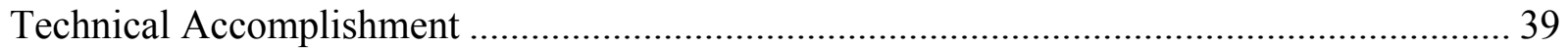

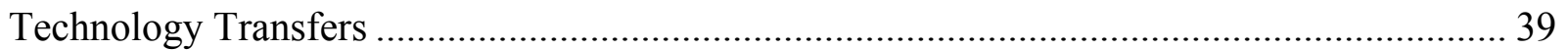

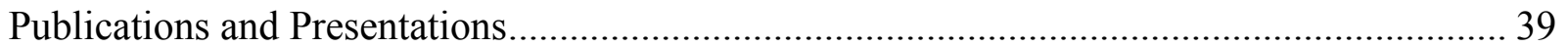

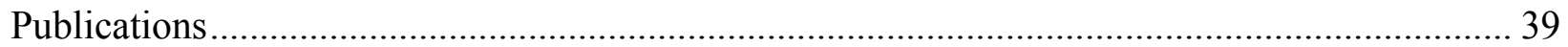

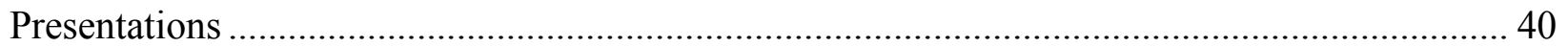

Summary, Conclusions and Recommendations...................................................................... 41

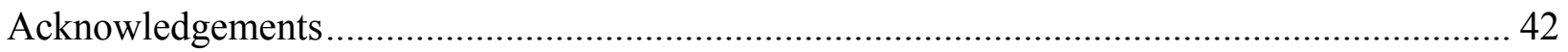

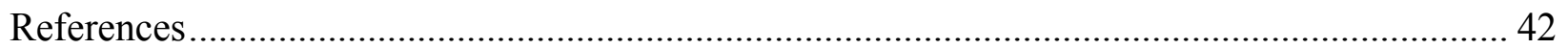




\section{Abbreviations and Acronyms}

ASME -American Society of Mechanical Engineers

ATC - Advanced Technology Corporation

DGS - DGS Metallurgical Solutions, Inc.

DOE - US Department of Energy

DOT - US Department of Transportation

NACE - National Association of Corrosion Engineers

ORNL - Oak Ridge National Laboratory

SEM - Scanning Electron Microscope

SNLL - Sandia National Laboratory - Livermore

TEM - Transmission Electron Microscope

HIC - Hydrogen Induced Cracking

FCGR - Fatigue Crack Growth Rate

YS - Yield Strength

TS - Tensile Strength

RA - Reduction in Area

$\mathrm{He}$ - Helium

$\mathrm{H}_{2}$ - Hydrogen Gas

psi - pounds per square inch

$\mathrm{Hz}-\mathrm{Hertz}$

NACE - National Association of Corrosion Engineers

CLR - Crack Length Ratio (ratio of measured crack lengths vs. the coupon length)

CSR - Crack Sensitivity Ratio (ratio of measured cracked cross sectional area vs. coupon cross sectional area)

CTR - Crack Thickness Ratio (ratio of measured crack thickness vs. the coupon thickness)

BHN - Brinell Hardness

\section{Microstructure Abbreviations}

AF- Acicular Ferrite

B - Bainite

P - Pearlite

PF - Polygonal Ferrite

UB - Upper Bainite 


\section{Executive Summary}

\section{Introduction}

Gaseous hydrogen is one of several potential fuel sources that can replace fossil fuels in several different sectors of the US economy, especially the transportation (automobiles) and home heating. Supply of these sectors would require large volumes of gaseous hydrogen to be moved economically to major metropolitan. Currently the most economical method for transmission of the volume of hydrogen gas required is under pressure through transmission steel pipelines. As transmission pressures are increased, steel pipelines that could be used for the transport of hydrogen at pressure can be prone to hydrogen embrittlement at the welds, the heat-affected-zone and/or the base metal regions of the pipeline. Over the past few years, significant advances have been made in understanding the mechanisms of hydrogen embrittlement in a wide variety of materials and in materials technologies. However, specific data related to traditional pipeline steels in the presence of gaseous hydrogen under pressure is lacking.

The original objectives of this project were as follows ${ }^{1}$ :

1. To identify steel compositions and associated welding filler wires and processes that would be suitable for construction of new pipeline infrastructure

2. To develop barrier coatings for minimizing hydrogen permeation in pipelines and to develop insitu deposition processes suitable for these coatings

3. To understand the cost factors related to the construction of new pipelines and modification of existing pipelines and to identify the path to cost reduction

In support of the three objectives, the following tasks were part of the original program:

1. Evaluate hydrogen embrittlement characteristics of existing commercial pipeline steels under high-pressure hydrogen

2. Develop and/or identify alternate alloys and evaluate hydrogen embrittlement

3. Develop coatings to minimize dissolution and penetration of hydrogen

4. Evaluate the hydrogen embrittlement in alloys coated with selected coatings

5. Perform financial analyses and incorporate knowledge into codes and standards

However, as the project further evolved and with valuable input from the DOE Pipeline Working Group, the key tasks that were agreed upon to focus the work of the project were modified as follows:

1. Evaluate hydrogen embrittlement characteristics of existing commercial pipeline steels under high-pressure hydrogen including the following:

a. Microstructural characterization - it is known that microstructures play a role in mechanical property performance in the presence of hydrogen.

b. Mechanical property testing

i. NACE TM0284 HIC Solution A Testing

ii. Tensile testing in the presence of gaseous hydrogen under pressure various pressures

iii. Fracture testing in the presence of gaseous hydrogen under pressure various pressures

iv. Fatigue testing in the presence of gaseous hydrogen under pressure various pressures

2. Share and incorporate knowledge into codes and standards 
Work related to barrier coatings, development of alternative alloys and financial analysis were place on hold.

\section{Research and Development}

Four commercially available pipeline steels along with two commercially available alternative steels (abrasion resistant and high strength structural steels) where selected for the original testing program. Steel samples for the six different alloys for the project along with material test reports were supplied by industry partner EVRAZ Oregon Steel Mills. The six steels, Table 1, were chosen based on their respective microstructural variations and in the case of the pipeline steels representation of recent commercial transmission pipeline microstructure designs. However, as stated prior focus was redirected toward working with the four commercially available pipeline steels labeled "A", "B", "C" and " $D$ " in Table 1.

Table 1: Six Steels in Original DOE Project

\begin{tabular}{|c|c|c|c|}
\hline $\begin{array}{c}\text { Project/ } \\
\text { Alloy ID }\end{array}$ & Grade & C & $\begin{array}{c}\text { Comment (Perception of } \\
\text { microstructure } \\
\text { performance in H2 gas) }\end{array}$ \\
\hline A & API X70 & 0.08 & Baseline \\
\hline B & API X70/X80 & 0.05 & Potentially Good \\
\hline C & API X70/X80 & 0.04 & Potentially Good \\
\hline D & API X60 HIC & 0.03 & Potentially Best \\
\hline E & 100 KSI Minimum Yield Strength Hot Rolled Structural Steel & 0.08 & Potential Alternative \\
\hline F & Quench and Tempered Abrasion Resistant 400 BHN & 0.15 & Potential Alternative \\
\hline
\end{tabular}

The first step of the project was to characterize the microstructures of the six different steels in the project. This was completed through project industry partner Reference Metals Company over the timeframe of the project. Optical microscopy, scanning electron microscopy (SEM) and transmission electron microscopy (TEM) were used to identify the various microstructural phases and to estimate volume fractions of the six different steels in Table 1. The characterization of the microstructures for the six different steels in the project resulted in the following volume fractions:

- Alloy A (API X70) - 92\% Polygonal Ferrite/8\% Upper Bainite

- Alloy B (API X70/X80) - 90\% Polygonal Ferrite $/ 10 \%$ Coarse Acicular Ferrite

- Alloy C (API X70/X80) - 90\% Polygonal Ferrite/10\% Coarse Acicular Ferrite with a very small amount of Pearlite

- Alloy D (API X60 HIC) - 100\% Polygonal Ferrite

- Alloy E (100 KSI Minimum Yield Strength Hot Rolled Structural Steel) - 100\% Acicular Ferrite

- Alloy F (Quench and Tempered Abrasion Resistant 400 BHN) - 80\% Acicular Ferrite/20\% Lath-type Bainite

Mechanical property testing of selected project alloys (pipeline steels only as noted prior that primary focus would be on the four pipeline steels for the project) were carried out by industry partner Advanced Technology Corporation (ATC) and Oak Ridge National Laboratory (ORNL). Advanced Technology Corporation uses a patented stress-strain microprobe automated ball indentation method for determining mechanical properties of metal. ORNL used the standard ASTM E8 round bar tensile test method for mechanical property determination.

High pressure gaseous hydrogen testing capabilities were developed by ATC and ORNL. The ATC approach consisted of machining disks from steel samples and placing them in specially developed chamber that could be pressurized up to 5000 psi with gaseous hydrogen and then testing using the SSM approach over time, Figure $\mathbf{1}^{2}$. ATC tested project alloy ID's A and D at 2000 psi hydrogen pressure for 
200 hours along with industry sample of seamless pipe API X80 and an ERW pipe API Gr B. Only the seamless API X80 showed any degradation in mechanical properties when exposed to hydrogen. The fracture toughness of the seamless API X80 fracture toughness as measured by $\mathrm{K}_{\mathrm{JC}}$ decreased $43 \%$ after 200 hours exposure. Strength actually increased slightly which would not be considered normal when exposed to hydrogen. Results of the four steels from the ATC SSM testing can be seen in Figure 2. One item that the ATC SSM hydrogen testing showed is that the degradation of fracture toughness performance happened within the first 25 hours of exposure and then leveled off after that. Additional exposure time did not seem to affect the remaining results. After a review of the ATC SSM testing results, it was determined by the group that this method may not be valid as an evaluation technique for the project and any additional testing was abandoned.
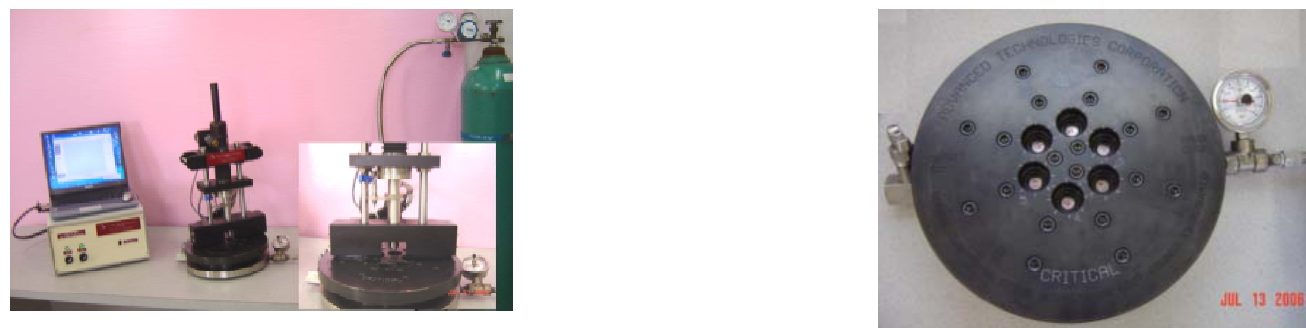

Fig. 1 - ATC SSM hydrogen testing apparatus. Picture on left shows set up, while picture on right shows details of pressurized hydrogen disk.

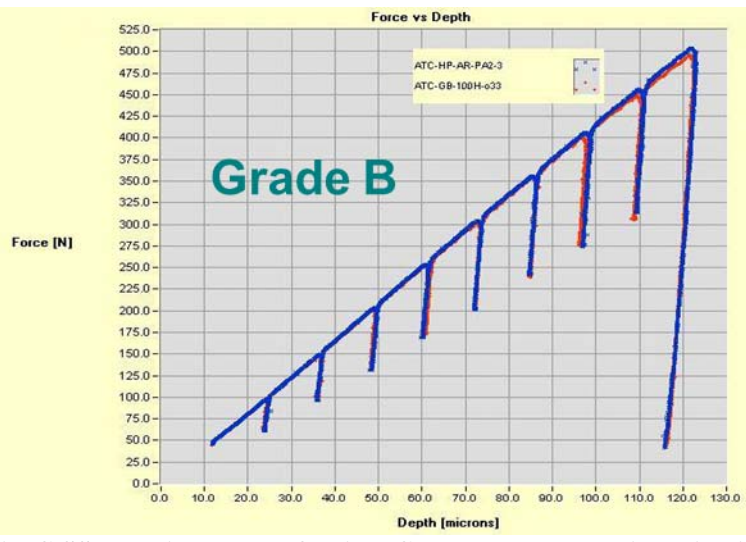

ATC SSM testing results for API Gr B ERW non-project pipeline steel. Note that both the red and blue lines are basically on top of each either signifying that the test method did not see any difference with exposure to 200 hours of 2000 psi hydrogen gas.

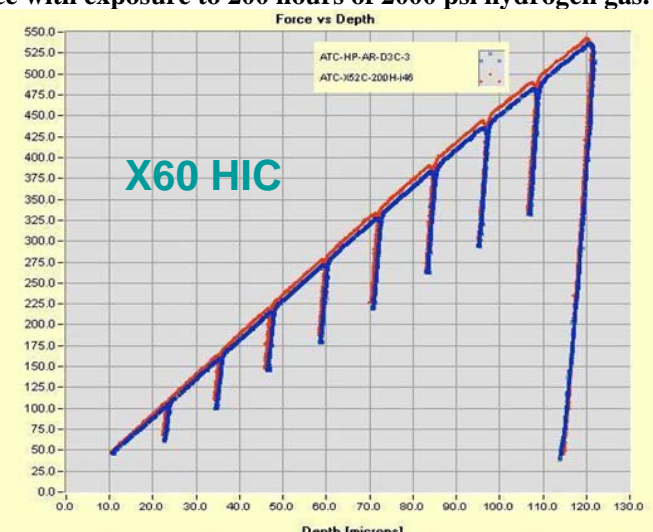

ATC SSM testing results for API X60 HIC LSAW project pipeline steel. Note that both the red and blue lines are basically on top of each either signifying that the test method did not see any difference with exposure to 200 hours of 2000 psi hydrogen gas.

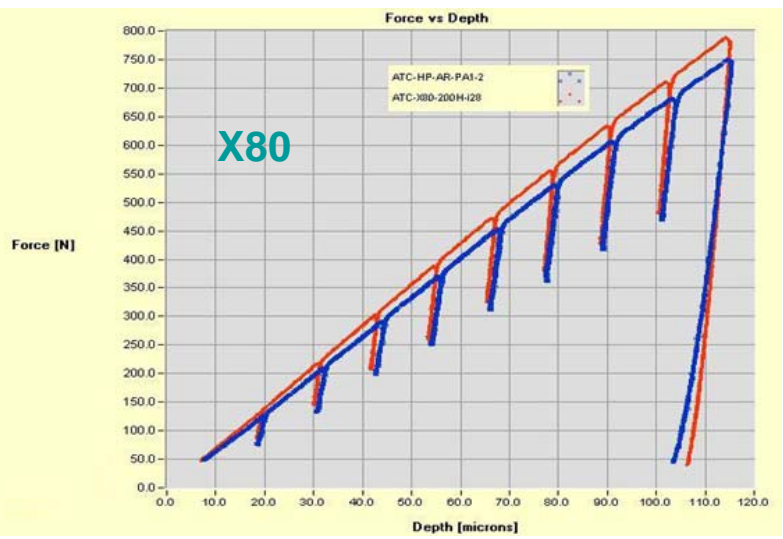

ATC SSM testing results for API X80 seamless non-project pipeline steel. Note that there is a separation between the red and blue lines signifying that the test method did see a difference with exposure to 200 hours of 2000 psi hydrogen gas.

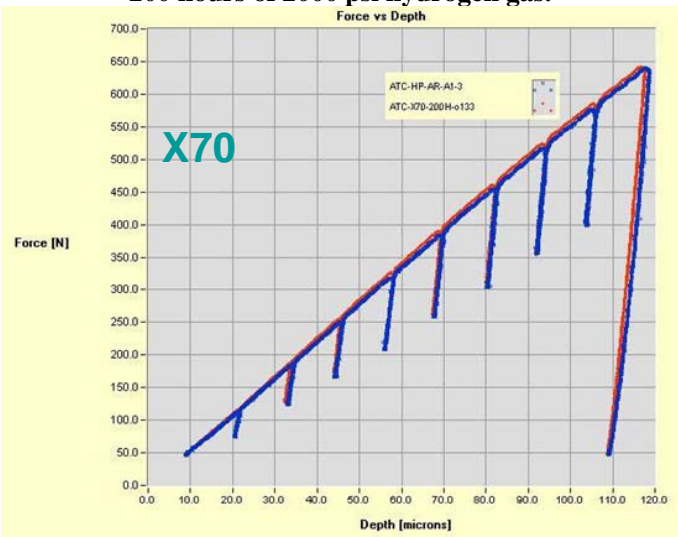

ATC SSM testing results for API X70 LSAW project pipeline steel. Note that both the red and blue lines are basically on top of each either signifying that the test method did not see any difference with exposure to 200 hours of 2000 psi hydrogen gas. 


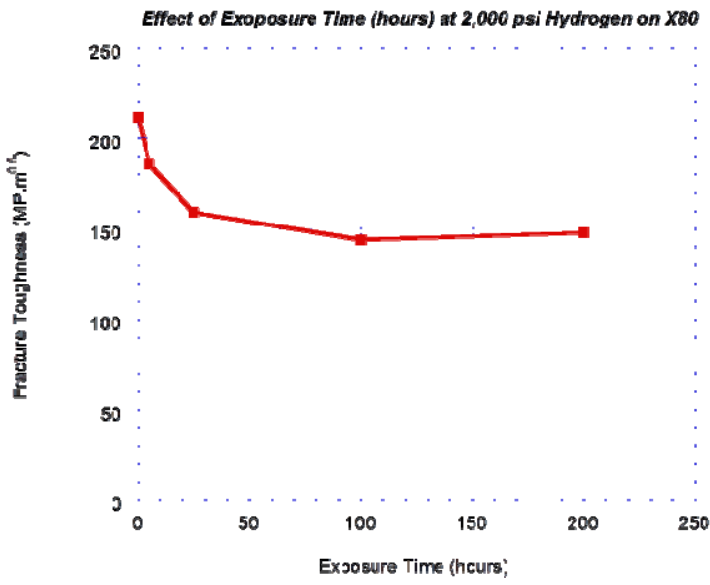

ATC SSM fracture toughness of API X80 seamless non-project pipeline steel results showing a $43 \%$ decrease in fracture toughness when exposed to hydrogen gas for 200 hours at 2000 psi hydrogen gas pressure.

Fig. 2 - ATC SSM Automated Ball Indentation test results in air and gaseous hydrogen for 200 hours at 2000 psi. Red lines represent air testing and blue lines represent gaseous hydrogen testing.

Ex-situ hydrogen and helium testing was carried out with partner Sandia National Laboratory Livermore (SNLL) on project pipeline steel Alloy's A, B and C. Parameters of the ex-situ testing conducted at SNLL were as follows:

- Hydrogen testing parameters
o Pressure - 20, $000 \mathrm{psi}(138 \mathrm{MPa})$
o Temperature $-100 \mathrm{C}$
o Duration of the testing -8 days
o Strain rate $-10^{-4} \mathrm{in} / \mathrm{in} / \mathrm{sec}$

- Helium testing parameters
o Pressure $-5000 \mathrm{psi}(34.5 \mathrm{MPa})$
o Temperature $-100 \mathrm{C}$
o Duration of the testing -8 days
o Strain rate $-10^{-4} \mathrm{in} / \mathrm{in} / \mathrm{sec}$

The results showed that microstructure did indeed have an effect on performance with project Alloy A showing instability in the stress-strain curve and project Alloy's B and C showing stable stress-strain curves, Figure $3^{3}$. 


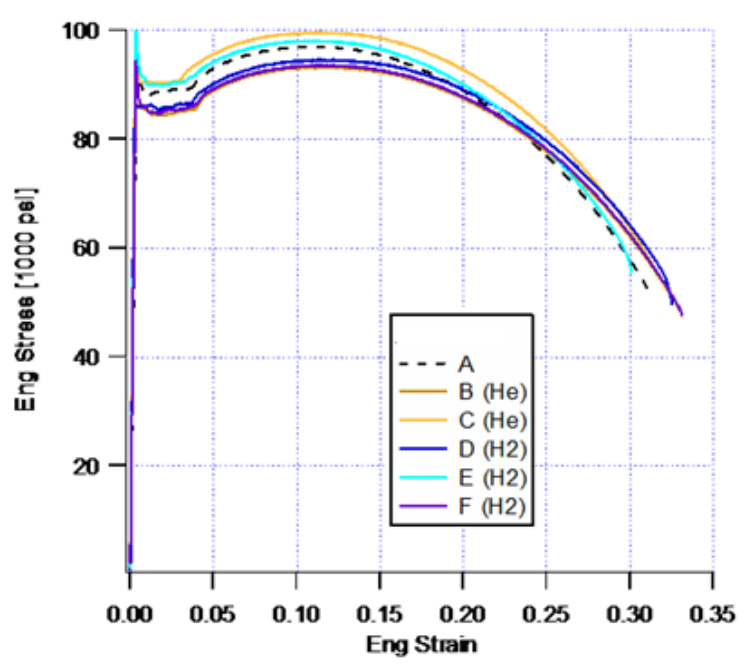

Project pipeline steel Alloy A, note the instability of the stress strain curve and degradation of strength with the exposure to hydrogen

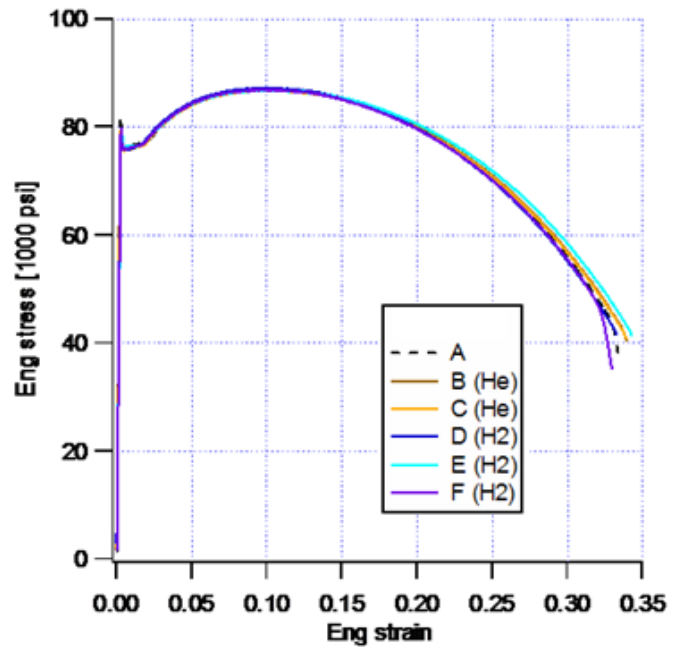

Project pipeline steel Alloy B, note the excellent stability of the stress strain curve and no degradation of strength with the exposure to hydrogen

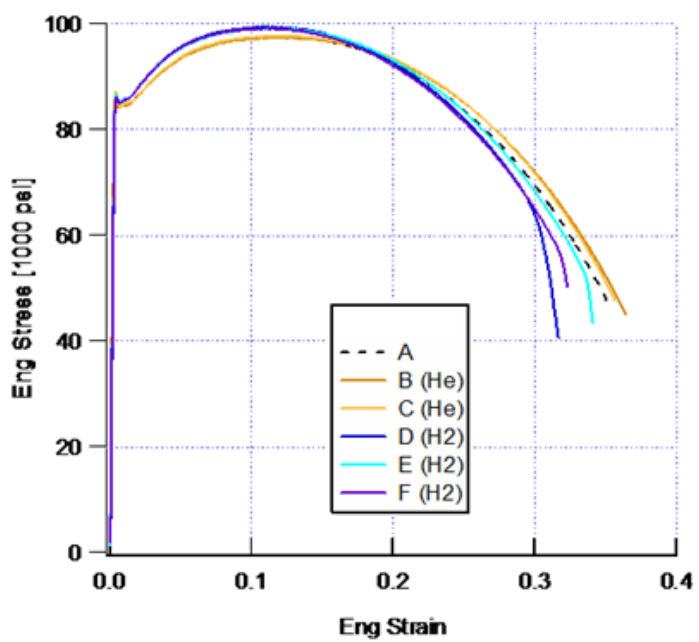

Project pipeline steel Alloy A, note the slight instability of the stress strain curve and slight degradation of strength with the exposure to hydrogen. This slight difference is most likely to the slight differences noted in microstructures between Alloy B and Alloy C.

Fig. 3 - Ex-situ hydrogen/helium testing conducted on project pipeline steel Alloy's A, B and C at SNLL

Standard NACE TM0284 Solution A (low pH) testing for resistance to hydrogen induced cracking of the four pipeline steels was conducted by industry partner EVRAZ Oregon Steel Mills. While this is a corrosive type HIC test and considered a more severe environment than a gaseous pressurized hydrogen environment absent of corrosion mechanism, it does give a relative idea of a given microstructure's resistant to hydrogen induced cracking. Regardless of how the hydrogen is introduced into the steel matrix, a microstructures ability to resist mechanical property degradation is the same. NACE TM0284 testing measures HIC resistance in the form of CLR (crack length ratio), CTR (crack thickness ratio) and CSR (crack sensitivity ratio). As expected the baseline Alloy A API X70 microstructure performed the worst in this type of testing. The other three pipeline steels (Alloy B, C and D) overall performed very well with mostly zero CLR, CTR and CSR results. The results of this testing strongly suggests that there would be microstructures that would have reasonable performance in a high pressure gaseous hydrogen environment. 
ORNL developed standard round bar tensile testing capability in an autoclave vessel capable of testing in pressurized gaseous hydrogen up to 5000 psi, Figure 4.
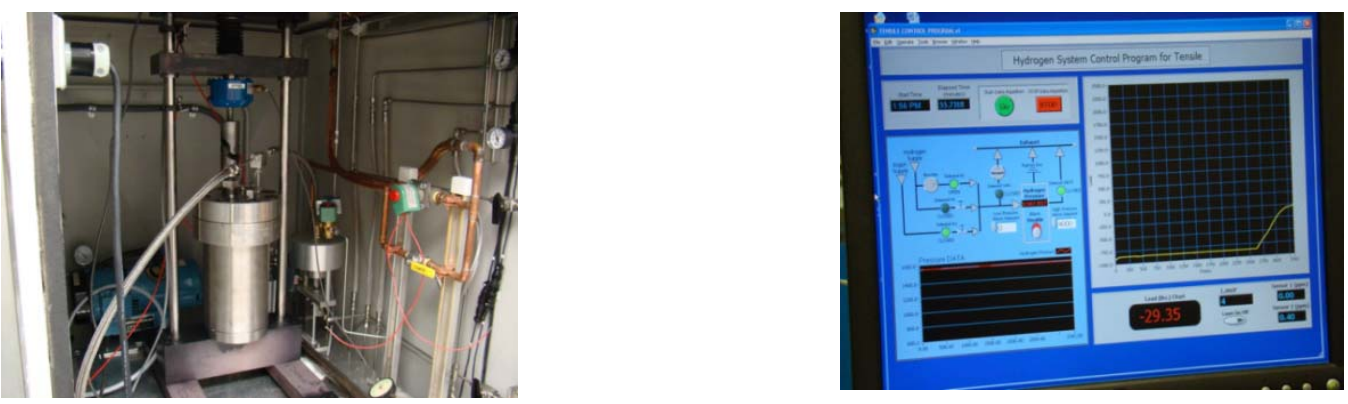

Fig. 4 - ORNL high pressure hydrogen tensile testing apparatus.

Using round bar tensile specimens, ORNL tested the four pipeline steels in air and then hydrogen pressures of $1600 \mathrm{psi}(11 \mathrm{MPa})$ and $3000 \mathrm{psi}(20.6 \mathrm{MPa})$. These two pressures were chosen based on input from the DOE Pipeline Working Group and partner ASME through the ASME B31.12 Hydrogen Piping and Pipeline Systems codes and standards committees as being reasonable and realistic potential operating pressures for hydrogen gas transmission. Initial testing at 1600 psi in hydrogen and helium of project pipeline steels Alloy's A and C with different strain rates at ORNL showed that the presence of hydrogen had an effect on the fracture features of the tensile specimen along with decreasing the total strain required for complete failure, Figure 5. Alloy $\mathrm{C}$ seemed to perform slightly better than Alloy A in this first initial testing.

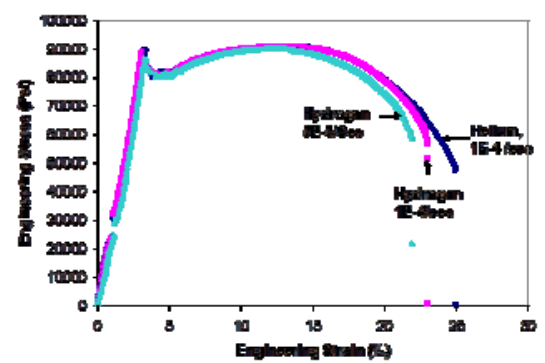

Project Alloy A API X70 pipeline steel tensile tested in hydrogen and helium at two different strain rates. Note that the presence of hydrogen decreases total strain needed for failure, regardless of strain rate.

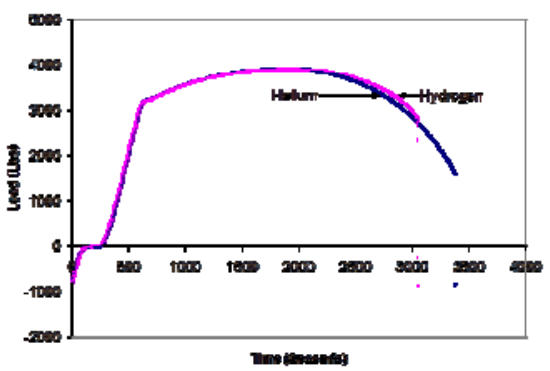

Project Alloy $\mathrm{C}$ at $\mathbf{1 0}^{-4}$ strain rate. Note that presences of hydrogen decreases total strain to failure.

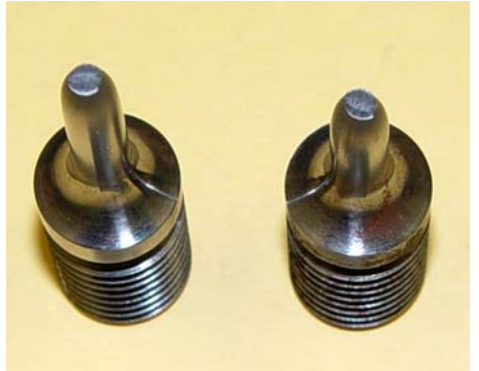

Helium Testing - Typical Ductile cup and cone fracture

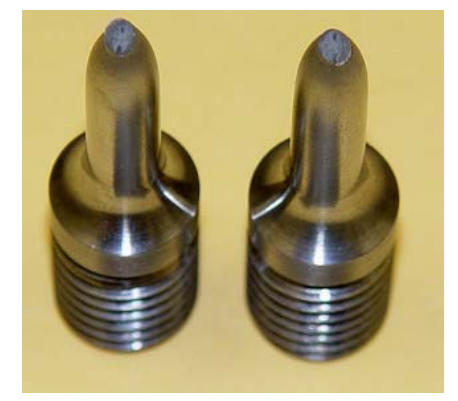

Helium Testing - Typical Ductile cup and cone fracture

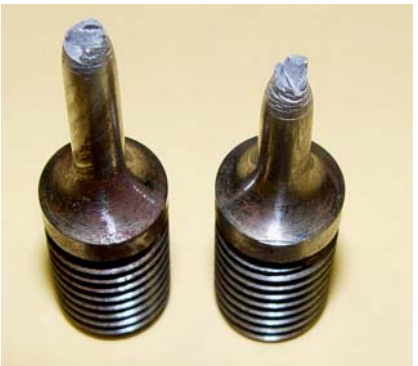

Hydrogen Testing - Faceted fracture surface with evidence for multiple secondary cracking

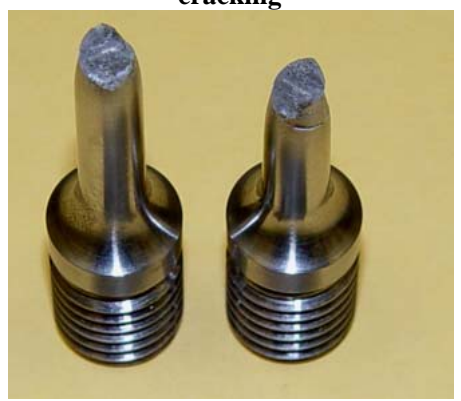

Hydrogen Testing - Faceted fracture surface with

evidence for multiple secondary cracking, does not seem as severe as in Alloy $\mathrm{A}$

Fig. 5 - Project Alloy's A and C tensile tested at 1600 psi hydrogen and helium at ORNL 
Based on this initial testing, a tensile testing matrix was developed for the four commercial pipeline steels Alloys A-D at ORNL. The details of the tensile testing matrix parameters are as follows:

- $\quad$ Three different test pressures (800 psi (5.5 MPa), 1600 psi (11 MPa), 3000 psi (20.7 MPa)

- Two different strain rates $\left(10^{-4}, 10^{-5}\right)$

- Two different gas mediums (hydrogen, helium)

The results of the tensile testing revealed the following effects of hydrogen on the four different project pipeline alloys/microstructures ${ }^{4}$ :

1. There was an initial decrease in reduction in area (RA) from testing in helium to 800 psi (5.5 $\mathrm{MPa}$ ) hydrogen gas testing for $A L L$ four alloys/microstructures and for both strain rates.

2. After the initial reduction in area decrease at $800 \mathrm{psi}(5.5 \mathrm{MPa})$, different microstructures performed differently with increasing hydrogen pressure up to $3000 \mathrm{psi}(20.7 \mathrm{MPa})$. Alloy B and D performing the best with increasing pressure.

3. There was no effect on actual yield and ultimate strength when exposed to hydrogen.

Figure 6 shows the results of the reduction in area tensile testing at three different hydrogen pressures and two different strain rates performed at ORNL.

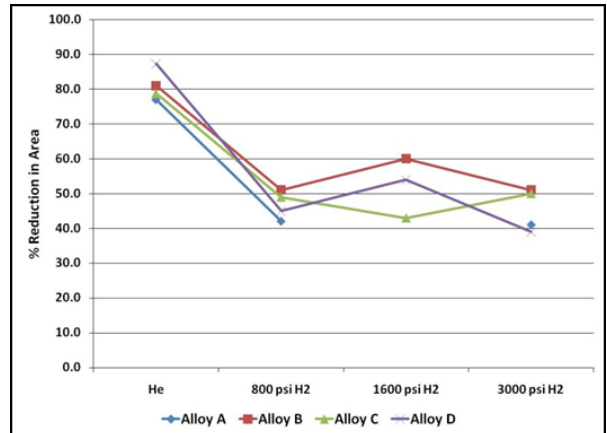

Reduction in area results four pipeline steel alloys/microstructures at $10^{-4}$ strain rate at various hydrogen pressures. Note the initial drop at 800 psi and then the performance with increasing pressure. Overall Alloy's B and $D$ perform the best with increasing pressure.

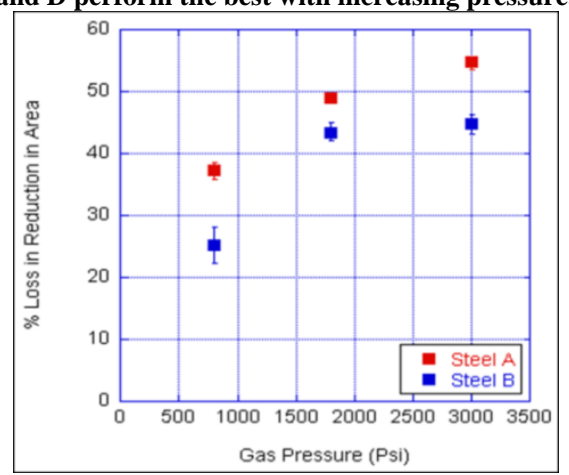

\% loss in reduction in area statistics of Alloy's A and B vs. hydrogen pressure at $10^{-5}$ strain rate. Note the overall stability of each result at pressure

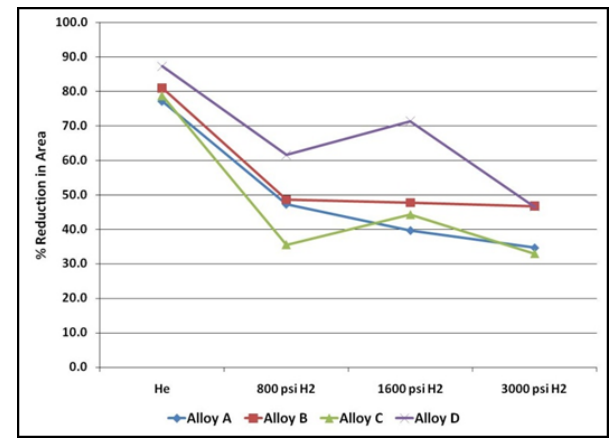

Reduction in area results four pipeline steel alloys/microstructures at $10^{-5}$ strain rate at various hydrogen pressures. Note the initial drop at 800 psi and then the performance with increasing pressure. Overall Alloy's B and $D$ perform the best with increasing pressure.

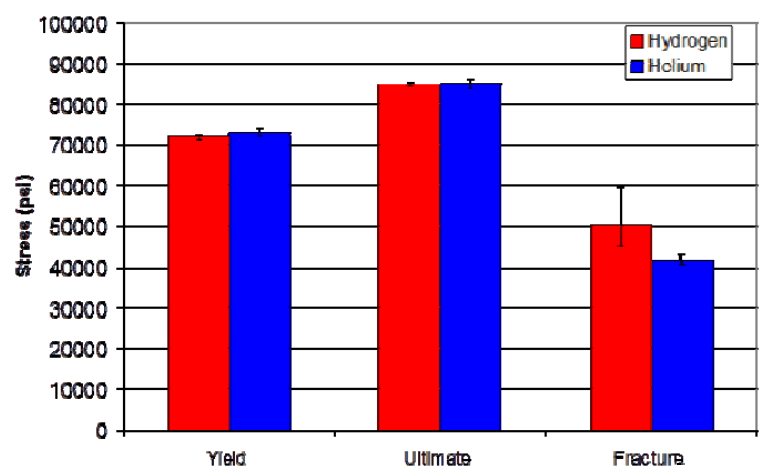

Example of strength changes for Alloy $B$ in hydrogen vs. helium at $10^{-5}$ strain rate. There is no effect on yield or ultimate strength only fracture stress in the presence of hydrogen.

Fig. 6 - Results of hydrogen/helium tensile testing at ORNL 
Based on the results of the ORNL testing and direction from the DOE Pipeline Working Group and driven by available funding, the two best performing alloys/microstructures from the ORNL tensile testing, Alloy's B and D were chosen for further testing ${ }^{5}$. The DOE Pipeline Working Group direction was to further test for fracture toughness and fatigue performance. Due to the type of hydrogen testing capability required for fracture toughness and fatigue testing project partner Sandia National Laboratory Livermore was enlisted for this phase of the project. SNLL has the necessary equipment and expertise to perform high pressure gaseous hydrogen fracture toughness and fatigue testing. Fracture toughness testing at SNLL was funded out of the original DOE project funding through a work for others agreement. Fatigue testing at SNLL was funded by project industry partner Reference Metals Company also through a work for others agreement. The SNLL fracture toughness and fatigue testing was conducted at $800 \mathrm{psi}$ and 3000 psi. These two pressures were chosen with input from the project partner ASME and more importantly input from ASME B31.12 Hydrogen Piping and Pipelines codes and standards committee. The two pressures would represent what would most likely be potential hydrogen transmission pipeline operating pressures.

The two project alloys chosen for the further evaluation at SNLL were Alloy's B and D. Alloy B was an API X70/X80 steel grade consisting of a microstructure of $90 \%$ polygonal ferrite $/ 10 \%$ coarse acicular ferrite. Alloy D was an API X60 HIC steel grade consisting of a microstructure of $100 \%$ polygonal ferrite. In the fracture toughness testing, both alloys performed reasonably well with $\mathrm{K}_{\mathrm{JQ}}$ values of 85-90 $\mathrm{MPa}-\mathrm{m}^{1 / 2}$ for Alloy D and 115-125 MPa-m ${ }^{1 / 2}$ for Alloy B at the two pressures, Figure 7.

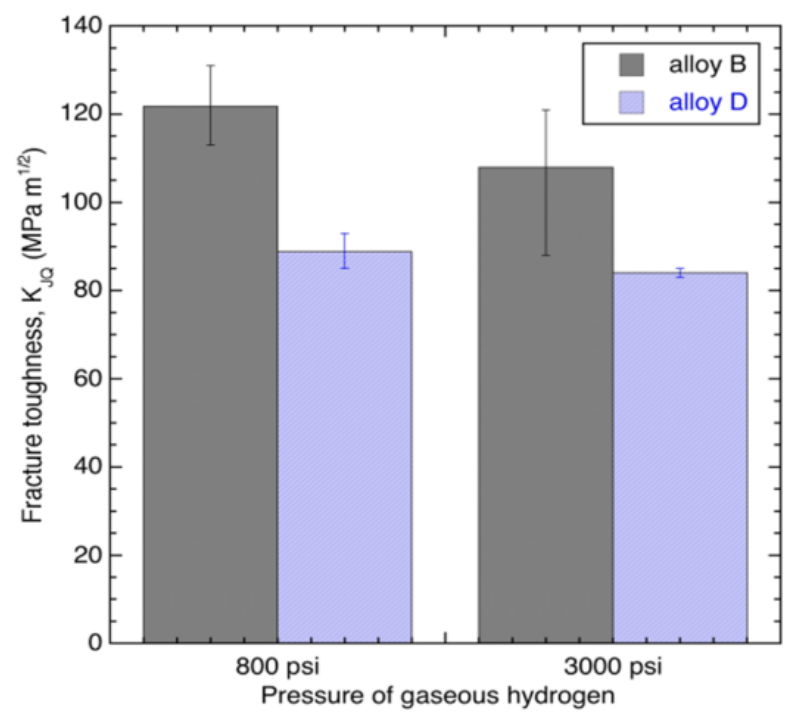

Fig. 7 - SNLL fracture toughness results at $800 \mathrm{psi}$ and $3000 \mathrm{psi}$ gaseous hydrogen pressure of project Alloy's B and D

SNLL, under a work for others agreement with funding through project partner Reference Metals Company, conducted fatigue testing utilizing two R-ratio values $(0.5$ and $0.1, \mathrm{R}$ is the ratio of the minimum to maximum load applied to the specimen) on Alloy's B and D at 800 and 3000 psi (5.5 and 21 $\mathrm{MPa}$ ). In addition, testing was completed in air for both alloys for comparison. There was no significant difference in fatigue results by R-ratio values or microstructures. However, both microstructures showed tendencies of convergence with those values generated in air at lower $\Delta \mathrm{K}$ values, Figure 8. 


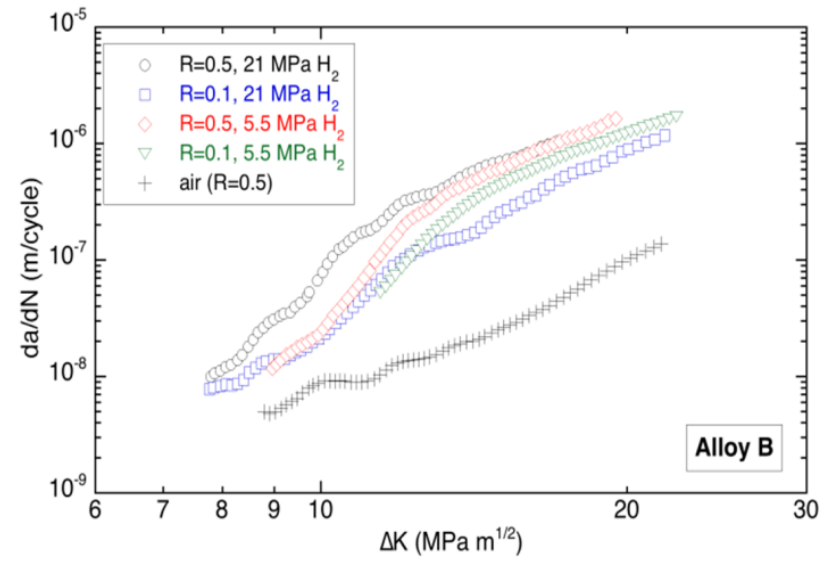

Measured Fatigue Crack Growth Rate in Hydrogen (800 and 3000 psi) and Air of Alloy B at two R-values

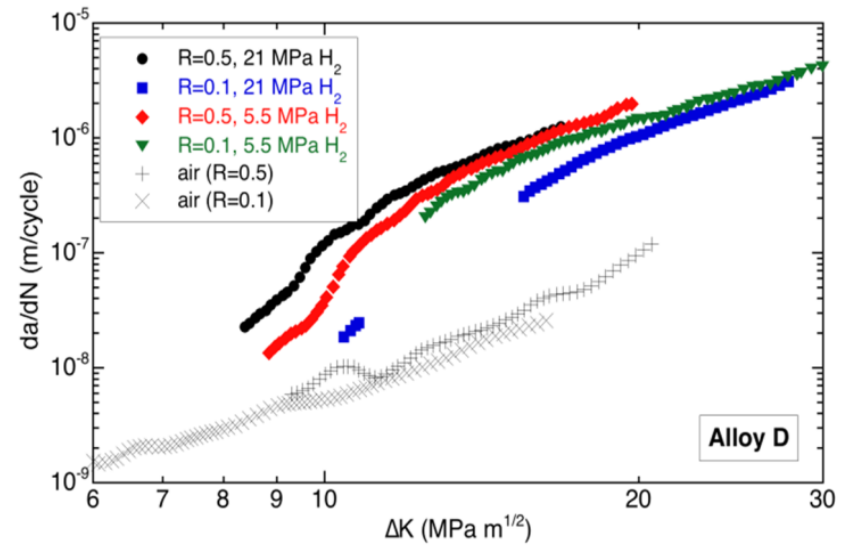

Measured Fatigue Crack Growth Rate in Hydrogen (800 and 3000 psi) and Air of Alloy D at two R-values

Fig. 8 - SNLL fatigue testing of project Alloy's B and D

The fracture toughness and fatigue testing of project Alloy's B and D concluded the available funding for the original DOE funded project. However, as this information was shared with industry and ASME codes and standards enough interest was generated to continue the work on the original project Alloy A while expanding the testing program to and additional ten different alloy/microstructure/processing of pipeline steels covering alloy/microstructure designs for transmission pipelines from the 1960's to 2010. Since fracture and fatigue results were of the most interest to those within the DOE Pipeline Working Group and ASME B31.12 Piping and Pipelines codes and standards committee, this would be the focus of this "Phase 2" research. The total package of research was covered under private sector funding from ASME and Reference Metals Company along with US DOT funding at SNLL and NIST. Figure 9 shows the total matrix of fracture and fatigue testing that has been completed or is in progress to be completed that developed from this original DOE funded research work. Yellow highlighting in the figure shows the original six alloys/microstructures with the orange highlighted areas showing the fracture and fatigue testing concluded with the original DOE funding plus some private sector funding. Blue and green shaded areas shows testing either completed or in progress funded through additional private sector funding along with DOT funding. As can be seen a significant number of alloy/microstructure designs, including one pressure vessel steel, have been or are in the process of being evaluated that would cover a wide range of possible alloy/microstructure designs in North America from the 1960's in the Phase 2 testing program. Included in this testing was induction bend pipe to evaluate the effect of the induction bending operation. The white highlighted/not tested are alloys/microstructures where there is not a significant amount of interest or no available funding to complete the testing (i.e. - seam/girth welds are areas of interest but no funding availability). 


\begin{tabular}{|c|c|c|c|c|c|c|c|}
\hline Item & $\begin{array}{c}\text { Project } \\
\text { Code }\end{array}$ & Grade & Microstructure & $\begin{array}{c}\text { Fracture } \\
\text { Test } 800 \text { psi } \\
\text { Location (2 } \\
\text { samples) }\end{array}$ & $\begin{array}{c}\text { Fracture Test } \\
3000 \text { psi } \\
\text { Location (2 } \\
\text { Samples) }\end{array}$ & $\begin{array}{c}\text { Fatigue } \\
\text { Testing } 800 \text { psi } \\
\text { Location (2 } \\
\text { samples) }\end{array}$ & $\begin{array}{c}\text { Fatigue } \\
\text { Testing } \\
3000 \text { psi } \\
\text { Location (2 } \\
\text { samples) }\end{array}$ \\
\hline 1 & A & $\begin{array}{c}\text { API - Late } 1990 \text { 's } \times 70 \\
\text { Design }\end{array}$ & $92 \% \mathrm{PF} / 8 \%$ UB & 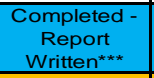 & $\begin{array}{c}\text { Completed - } \\
\text { Report } \\
\text { Written*** } \\
\end{array}$ & $\begin{array}{l}\text { In-progress - } \\
\text { NIST }\end{array}$ & $\begin{array}{l}\text { In-progess - } \\
\text { NIST }\end{array}$ \\
\hline 2 & B & \begin{tabular}{|} 
API - 2000's X70/X80 \\
w/o Moly Design, Lo Cr
\end{tabular} & $90 \% \mathrm{PF} / 10 \% \mathrm{CAF}$ & Completed $^{\star}$ & Completed* & Completed* & Completed* \\
\hline 3 & C & $\begin{array}{l}\mathrm{API}-2000 \text { 's } \times 70 / \times 80 \\
\text { w/o Moly Design, } \mathrm{Hi} \mathrm{Cr}\end{array}$ & $\begin{array}{c}90 \% \text { PF/10\% CAF+ } \\
\text { Sm UB }\end{array}$ & Not Tested & Not Tested & Not Tested & Not Tested \\
\hline 4 & $\mathrm{D}$ & $\begin{array}{c}\text { API - Current } \times 60 \text { HIC } \\
\text { Design }\end{array}$ & $100 \% \mathrm{PF}$ & Completed $^{\star}$ & Completed* & Completed* & Completed* \\
\hline 5 & Secat $E$ & $\begin{array}{c}\text { Structural } 100 \mathrm{KSI} \\
\text { Design }\end{array}$ & $100 \% \mathrm{AF}$ & Not Tested & Not Tested & Not Tested & Not Tested \\
\hline 6 & Secat F & $\begin{array}{l}400 \text { BHN Abrasion } \\
\text { Resistant Design }\end{array}$ & $\begin{array}{c}80 \% \text { AF/2O\% Lath } \\
\text { Type Bainite }\end{array}$ & Not Tested & Not Tested & Not Tested & Not Tested \\
\hline 7 & Sandia E & $\begin{array}{c}\text { API - 2000's } \times 70 / \times 80 ~ w \\
\text { Moly Design }\end{array}$ & $100 \%$ FAF & $\begin{array}{c}\text { Completed - } \\
\text { Report } \\
\text { Written } \\
\end{array}$ & Completed ${ }^{\star \star}$ & $\begin{array}{l}\text { In-progress - } \\
\text { NIST }\end{array}$ & Completed ${ }^{\star \star}$ \\
\hline 8 & Sandia F & $\begin{array}{c}\text { API - 2000's X70/X80 w/o } \\
\text { Moly Design }\end{array}$ & $30 \%$ PF/70\% FAF & \begin{tabular}{c|} 
Completed - \\
Report \\
Written \\
\end{tabular} & Completed $^{\star \star}$ & In-progress -NIST & $\begin{array}{c}\text { In-progress - } \\
\text { NIST }\end{array}$ \\
\hline 9 & G & $\begin{array}{c}\text { API - 1980's X70 Alloy } \\
\text { Design }\end{array}$ & $90 \% \mathrm{PF} / 10 \% \mathrm{P}$ & \begin{tabular}{c|} 
Completed - \\
Report \\
Written*** \\
\end{tabular} & $\begin{array}{c}\text { Completed - } \\
\text { Report } \\
\text { Written } \\
\end{array}$ & In-progress -NIST & $\begin{array}{l}\text { In-progress - } \\
\text { NIST }\end{array}$ \\
\hline 10 & $\mathrm{H}$ & $\begin{array}{c}\text { API - 1960's X52 Alloy } \\
\text { Design }\end{array}$ & $70 \%$ PF/30\% P & \begin{tabular}{|c|} 
Completed - \\
Report \\
Written $^{\star \star \star}$ \\
\end{tabular} & $\begin{array}{c}\text { Completed - } \\
\text { Report } \\
\text { Written*** } \\
\end{array}$ & In-progress -NIST & $\begin{array}{l}\text { In-progress - } \\
\text { NIST }\end{array}$ \\
\hline 11 & 1 & $\begin{array}{c}\text { API - Early 1990's X70 } \\
\text { Design }\end{array}$ & $85 \% \mathrm{PF} / 15 \% \mathrm{P}$ & $\begin{array}{c}\text { Completed - } \\
\text { Report } \\
\text { Written** }\end{array}$ & 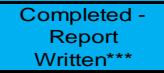 & In-progess - NIST & $\begin{array}{l}\text { In-progess - } \\
\text { NIST }\end{array}$ \\
\hline 12 & $\mathrm{~J}$ & $\begin{array}{c}\text { API - 1990's/2000's X52 } \\
\text { Alloy Design }\end{array}$ & $92 \% \mathrm{PF} / 5 \% \mathrm{AF} / 3 \% \mathrm{P}$ & $\begin{array}{c}\text { Completed - } \\
\text { Report } \\
\text { Written*** }\end{array}$ & Completed & In-progess - NIST & Completed \\
\hline 13 & K & $\begin{array}{l}\text { PV - ASTM A516 Gr70 } \\
\text { w/o microalloy }\end{array}$ & PF/P (40+\%) TBD & Not Tested & Not Tested & Not Tested & Not Tested \\
\hline 14 & L & $\begin{array}{l}\text { PV - ASTM A516 Gr70 } \\
\text { with microalloy }\end{array}$ & $40 \% \mathrm{PF} / 60 \% \mathrm{P}$ & \begin{tabular}{c|} 
Completed - \\
Report \\
Written
\end{tabular} & $\begin{array}{c}\text { Completed - } \\
\text { Report } \\
\text { Written*** }\end{array}$ & Not Tested & Not Tested \\
\hline 15 & M & $\begin{array}{c}\text { API X70 - Pipeline Long } \\
\text { Seam Welds } \\
\end{array}$ & As-castTBD & Not Tested & Not Tested & Not Tested & Not Tested \\
\hline 16 & N & API - Pipeline Girth Welds & As-castTBD & Not Tested & Not Tested & Not Tested & Not Tested \\
\hline 18 & $P$ Ind & $\begin{array}{l}\text { Induction Bend } \\
\text { Comparison X52 }\end{array}$ & $95 \% \mathrm{PF} / 5 \% \mathrm{AF}$ & \begin{tabular}{c|} 
Completed - \\
Report \\
Written \\
\end{tabular} & $\begin{array}{c}\text { Completed - } \\
\text { Report } \\
\text { Written } \\
\end{array}$ & In-progress -NIST & $\begin{array}{c}\text { In-progress - } \\
\text { NIST }\end{array}$ \\
\hline 19 & P Nind & $\begin{array}{l}\text { Non-Induction Bend } \\
\text { Comparison } \times 52\end{array}$ & $90 \% \mathrm{PF} / 10 \% \mathrm{AF}$ & \begin{tabular}{c|} 
Completed - \\
Report \\
Written
\end{tabular} & $\begin{array}{l}\text { Completed - } \\
\text { Report } \\
\text { Written }{ }^{\star \star \star}\end{array}$ & In-progess - NIST & $\begin{array}{l}\text { In-progess - } \\
\text { NIST }\end{array}$ \\
\hline
\end{tabular}

\section{Fig. 9 - Matrix of original DOE funded fracture/fatigue testing plus "Phase 2" fracture/fatigue testing from additional private sector/DOT funding.}

\section{Technology Transfer}

During the entire project as data was being generated along with the additional information generated in the non-DOE funded "Phase 2" program, the testing parameters and results have been shared with various organizations/team members. Presentations have been made at each US DOE Annual Peer Review Meeting, at each DOE Pipeline Working Group meeting, paper/presentations at ASME PVP 2009, 2010, 2011 and the upcoming 2013 conferences, ASME International Pipeline Conferences in 2010 and 2012, 2008 and 2012 International Hydrogen Conference and with the ASME B31.12 Piping and Pipelines codes and standards committee. Project partner DGS Metallurgical Solutions, Inc. is a member of the ASME B31.12 codes and standards committee and is working with the committee to make guidance language modifications to the existing B31.12 code based on the results of the work from the original DOE funded project and additional "Phase 2" work. The ASME B31.12 committee has representation from three large industrial hydrogen producers which have access to the data generated by the initial program and the "Phase 2" program demonstrating the importance of proper microstructure selection in optimizing the design of hydrogen piping and pipeline systems. 


\section{Summary, Conclusions and Recommendations}

This originally funded DOE work coupled with the additional Phase 2 work has significantly increased the understanding of the role of steel alloy designs, microstructures and mechanical property performance when exposed to gaseous hydrogen in the pressure ranges of $800-3000$ psi. Even though there is mechanical property degradation with initial exposure to hydrogen for all steels evaluated, mechanical property performance of certain microstructures can become stable with increasing hydrogen pressure. Mechanical property performance of certain microstructures may be more than adequate to perform safely for hydrogen gas service applications. This strongly implies that pipeline steels that exist in some of the current North American transmission pipeline infrastructure may be suitable for gaseous hydrogen transportation. It also strongly suggests that current pipeline steel technology can be used to develop microstructures that have suitable mechanical properties in the presence of gaseous hydrogen in pressures up to 3000 psi.

From this original DOE funded work the following conclusions can be made:

1. Pipeline steel microstructures evaluated in the project all experienced an initial degradation in mechanical properties with initial exposure to hydrogen gas under pressure (800 psi) as measured by reduction in area tensile testing.

2. However, once the initial degradation was reached, microstructures behaved differently with continued increasing hydrogen pressure up to 3000 psi.

3. Microstructures of polygonal ferrite and/or acicular ferrite with no presence of upper bainite or pearlite performed the best in hydrogen pressures up to $3000 \mathrm{psi}$ as measured by reduction in area tensile testing.

4. Absolute yield and ultimate strength were not affected by exposure to hydrogen; only the stress to final fracture was affected by hydrogen.

5. Fracture toughness varied by microstructure with slight decreases in toughness with increasing hydrogen pressure for each of the two microstructures tested.

6. Fatigue testing between the two microstructures with two different frequencies and pressures showed no significant difference when exposed to hydrogen.

7. Since fatigue was not significant between the two microstructures then microstructure design to optimize fracture toughness can be considered. A polygonal ferrite/acicular ferrite microstructure generated the highest fracture toughness values up to 3000 psi of the two microstructures evaluated.

8. Increasing yield strength did not affect the fracture toughness performance in hydrogen up to 3000 psi as has been reported previously by others.

9. Even though the polygonal ferrite/acicular ferrite microstructure performed the best in this evaluation, this does not necessarily mean that some of the other microstructures are not suitable for hydrogen service. Suitability will have to be determined by the requirements of the

Based on the project work, the following recommendations can be made:

1. Correlations need to be developed between the fracture toughness/fatigue test results with those of a more traditional steel testing technique such as the V-notch Charpy toughness testing. The standard steel testing protocol then can be used in developing specifications.

2. Additional steel microstructures have been evaluated for fracture toughness since this original project, however, as illustrated in Figure $\mathbf{9}$ there are still additional alloys/microstructures and probably a few more added to the matrix (X70 induction bend pipe as an example) that should be evaluated.

3. Fatigue testing needs to be completed as illustrated in the Figure 9 matrix. 
4. Various seam and girth welds need to be evaluated at 800 and 3000 psi. This includes submerged arc welded material along with other field welding techniques and consumable combinations.

5. Based on this work along with the additional work done in Phase 2, a clearer picture is developing of what an optimum metallurgical/alloy/microstructure hydrogen transmission pipeline may look like. A small (30-35 pipe lengths of a standard 40 feet length) rectangular demonstration pipeline should be built complete with a compressor station and monitoring equipment based on current knowledge and understanding. This line could be built and monitored at a national laboratory site such as Sandia National Laboratory - Livermore.

\section{Project Discussion}

\section{Background}

The continued growth of the world's developing countries has placed an ever increasing demand on traditional fossil fuels. This increased demand for fossil fuels has led to increasing research and development of alternative energy sources. Hydrogen gas is one of the potential alternatives under development. It is anticipated that the least expensive method of transporting large quantities of hydrogen gas is through steel pipelines. It is well known that hydrogen embrittlement has the potential to degrade steel's mechanical properties. Consequently, the current pipeline infrastructure used in hydrogen transport is typically operated in a conservative fashion, in particular lower operating pressures, lower strength steels, and heavier pipe wall thicknesses. This operational practice is not conducive to economical movement of significant volumes of hydrogen gas as an alternative to fossil fuels.

The degradation of the mechanical properties of steels in hydrogen service depends on the microstructure of the steel. An understanding of the relationship of mechanical property degradation of a given microstructure on exposure to hydrogen gas under pressure can be used to evaluate the suitability of the existing pipeline infrastructure for hydrogen service and guide alloy and microstructure design for new hydrogen pipeline infrastructure. To this end, the microstructures of relevant steels and their mechanical properties in relevant gaseous hydrogen environments must be fully characterized to establish suitability for transporting hydrogen.

A project to evaluate four commercially available pipeline steels alloy/microstructure performance in the presences of gaseous hydrogen has been funded by the US Department of Energy along with the private sector. The microstructures of four pipeline steels were characterized and tensile testing was conducted in gaseous hydrogen and helium at pressures of $5.5 \mathrm{MPa}(800 \mathrm{psi}), 11 \mathrm{MPa}(1600 \mathrm{psi})$ and $20.7 \mathrm{MPa}(3000$ psi). Based on reduction of area, two of the four steels that performed the best across the pressure range were selected for evaluation of fracture and fatigue performance in gaseous hydrogen at 5.5 MPa (800 psi) and 20.7 MPa (3000 psi).

\section{Introduction}

For both economic and environmental reasons, alternative energy sources to fossil fuels need to be developed. One potential energy source for the transportation sector is hydrogen gas. The US Department of Energy, over the past several years, has been funding research and development efforts in both fuel cell technology and hydrogen delivery systems. On the delivery side of the hydrogen as a fuel source equation, the most economical method to move large volumes of gas is through a pipeline infrastructure. 
The majority of today's pipeline infrastructure is made of steel. Degradation of the mechanical properties of the steel is always a concern when exposed to hydrogen gas. To address this concern a project funded by both the DOE and the private sector has been evaluating commercial grade pipeline steels' performance in the presence of pressurized hydrogen gas. The project is coordinated by Secat, Inc. with key partners from the private/industrial sector: University of Illinois, Oak Ridge National Laboratory, Oak Ridge, TN, Reference Metals Company, Pittsburgh, PA, Sandia National Laboratory, Livermore, CA, and DGS Metallurgical Solutions, Inc in Vancouver, WA.

The main objective of the study is as follows: Identify steel compositions/microstructures suitable for construction of new pipeline infrastructure and evaluate the potential use of the existing steel pipeline infrastructure in high pressure gaseous hydrogen applications.

To address the objective, four commercially available pipeline steels along with two commercially available structural steels were selected for evaluation. The selection of the six steels was based on the expected performance of each microstructure in the presence of gaseous hydrogen. It is known from the literature and experiences that microstructure along with internal steel cleanliness of the alloy play a major role in the interaction of hydrogen in the matrix and subsequent mechanical property performance ${ }^{6,7}$. A general description of each alloy selected can be found in Table 2. The comments in the table are in regard to the expected performance of each grade in the presence of gaseous hydrogen under pressure and are based on the perception of microstructure and performance experiences in a NACE TM0284 corrosion hydrogen environment. Final microstructural verification was part of the project evaluation and will be presented in a later section.

Table 2: Six Steels in Original DOE Project

\begin{tabular}{|c|c|c|c|}
\hline $\begin{array}{c}\text { Project } \\
\text { ID }\end{array}$ & Grade & C & $\begin{array}{c}\text { Comment (Perception of microstructure } \\
\text { performance in } \mathbf{H}_{\mathbf{2}} \text { gas) }\end{array}$ \\
\hline A & API X70 & 0.08 & Baseline \\
\hline B & API X70/X80 & 0.05 & Potentially Good \\
\hline C & API X70/X80 & 0.04 & Potentially Good \\
\hline D & API X60 HIC & 0.03 & Potentially Best \\
\hline E & 100 KSI Hot Rolled Structural Steel & 0.08 & Potential Alternative \\
\hline F & Abrasion Resistant 400 BHN & 0.15 & \\
\hline
\end{tabular}

Details of chemistry and microstructural characterization of the four pipeline steels can be seen in Table 3.

Table 3: Details of Six Commercial Grade Steels to be evaluated in Hydrogen Study

\begin{tabular}{|c|c|c|c|c|c|c|c|c|c|}
\hline $\begin{array}{c}\text { Project } \\
\text { ID }\end{array}$ & Grade & $\mathbf{C}$ & $\mathbf{M n}$ & $\mathbf{P}$ & $\mathbf{S}$ & $\mathbf{N b}$ & $\mathbf{V}$ & Other & Microstructure \\
\hline $\mathbf{A}$ & API X70 & 0.08 & 1.61 & 0.010 & 0.002 & 0.061 & 0.050 & $\mathrm{Si}, \mathrm{Ti} \leq 0.29$ & $\begin{array}{c}92 \% \text { Polygonal Ferrite/8\% } \\
\text { Upper Bainite }\end{array}$ \\
\hline B & API X70/X80 & 0.05 & 1.52 & 0.007 & 0.003 & 0.092 & 0.001 & $\mathrm{Si}, \mathrm{Cu}, \mathrm{Ni}, \mathrm{Cr}, \mathrm{Ti} \leq 0.75$ & $\begin{array}{c}90 \% \text { Polygonal Ferrite/10\% } \\
\text { Coarse Acicular Ferrite }\end{array}$ \\
\hline C & API X70/X80 & 0.04 & 1.61 & 0.010 & 0.002 & 0.096 & 0.001 & $\mathrm{Si}, \mathrm{Cu}, \mathrm{Ni}, \mathrm{Cr}, \mathrm{Ti} \leq 0.92$ & $\begin{array}{c}90 \% \text { Polygonal Ferrite/10\% } \\
\text { Coarse Acicular Ferrite with a } \\
\text { very small amount of Pearlite }\end{array}$ \\
\hline D & API X60 HIC & 0.03 & 1.14 & 0.008 & 0.001 & 0.084 & $\mathrm{NIA}$ & $\mathrm{Si}, \mathrm{Cu}, \mathrm{Ni}, \mathrm{Cr}, \mathrm{Ti} \leq 0.73$ & $100 \%$ Polygonal Ferrite \\
\hline E & $\begin{array}{c}100 \text { KSI Hot } \\
\text { Rolled } \\
\text { Structural } \\
\text { Steel }\end{array}$ & 0.08 & 1.71 & 0.011 & 0.005 & 0.044 & $\mathrm{NIA}$ & $\mathrm{Si}, \mathrm{Ni}, \mathrm{Ti}, \mathrm{B} \leq 0.93$ & $100 \%$ Acicular Ferrite \\
\hline F & $\begin{array}{c}\text { Abrasion } \\
\text { Resistant } 400 \\
\text { BHN }\end{array}$ & 0.15 & 1.42 & 0.014 & 0.004 & 0.014 & $\mathrm{NIA}$ & $\mathrm{Si}, \mathrm{Cr}, \mathrm{Mo}, \mathrm{Ti}, \mathrm{B} \leq 1.00$ & $\begin{array}{c}80 \% \text { Acicular Ferrite/20\% } \\
\text { Lath-type Bainite }\end{array}$ \\
\hline
\end{tabular}


After discussions and input from the DOE Hydrogen Project Management and DOE Pipeline Working Group it was decided that with available funding the focus of the project would only be on the four commercially available transmission pipeline steels, Project ID's A-D in Table 3.

The basic format for this phase of the study is as follows:

- Microstructural characterization of volume fraction of phases in each alloy

- Tensile testing of all four alloys in $\mathrm{He}$ and $\mathrm{H}_{2}$ at $5.5 \mathrm{MPa}(800 \mathrm{psi}), 11 \mathrm{MPa}$ (1600 psi), and 20.7 MPa (3000 psi). RA performance was used to choose the two best performers for further mechanical property evaluation.

- Fracture testing (ASTM E1820) of two best tensile test performers in $\mathrm{H}_{2}$ at $5.5 \mathrm{MPa}$ (800 psi) and $20.7 \mathrm{MPa}(3000 \mathrm{psi})$.

- Fatigue testing (ASTM E647) of two best tensile test performers in $\mathrm{H}_{2}$ at $5.5 \mathrm{MPa}$ (800 psi) and 20.7 $\mathrm{MPa}(3000 \mathrm{psi})$ with frequency $=1.0 \mathrm{~Hz}$ and R-ratio $=0.5$ and 0.1 .

In the results section of the paper, the project codes Alloy A, B, C, and D are used to identify the four steels that were evaluated.

\section{Initial Hydrogen Testing at ATC, ORNL and SNLL}

High pressure gaseous hydrogen testing capabilities were developed by ATC and ORNL. The ATC approach consisted of machining disks from steel samples and placing them in specially developed chamber that could be pressurized up to 5000 psi with gaseous hydrogen and then testing using the SSM approach over time, Figure 10. ATC tested project alloy ID's A and D at 2000 psi hydrogen pressure for 200 hours along with industry sample of seamless pipe API X80 and an ERW pipe API Gr B. Only the seamless API X80 showed any degradation in mechanical properties when exposed to hydrogen. The fracture toughness of the seamless API X80 fracture toughness as measured by $\mathrm{K}_{\mathrm{JC}}$ decreased $43 \%$ after 200 hours exposure. Strength actually increased slightly which would not be considered normal when exposed to hydrogen. Results of the four steels from the ATC SSM testing can be seen in Figure 11. One item that the ATC SSM hydrogen testing showed is that the degradation of fracture toughness performance happened within the first 25 hours of exposure and then leveled off after that. Additional exposure time did not seem to affect the remaining results. After a review of the ATC SSM testing results, it was determined by the group that this method may not be valid as an evaluation technique for the project and any additional testing was abandoned.
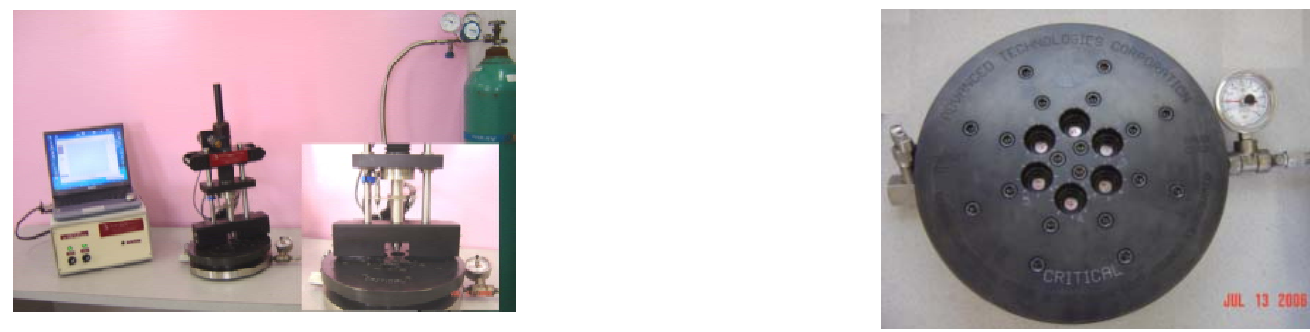

Fig. 10 - ATC SSM hydrogen testing apparatus. Picture on left shows set up, while picture on right shows details of pressurized hydrogen disk. 


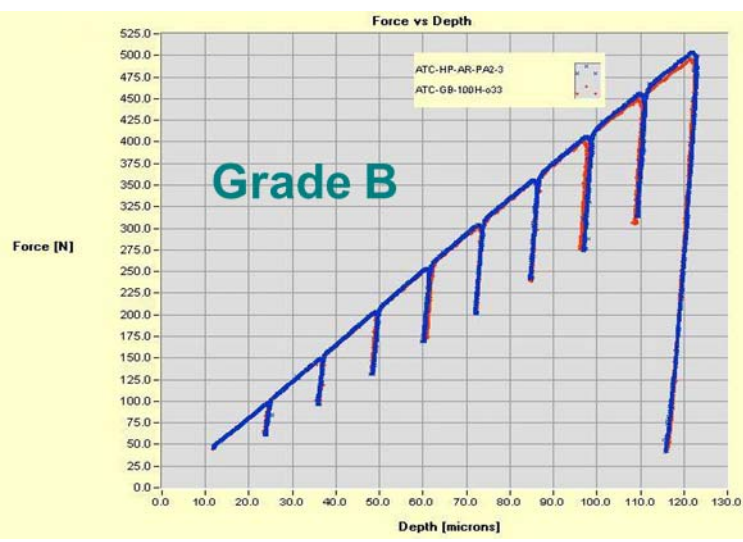

ATC SSM testing results for API Gr B ERW non-project pipeline steel. Note that both the red and blue lines are basically on top of each either signifying that the test method did not see any difference with exposure to 200 hours of 2000 psi hydrogen gas.

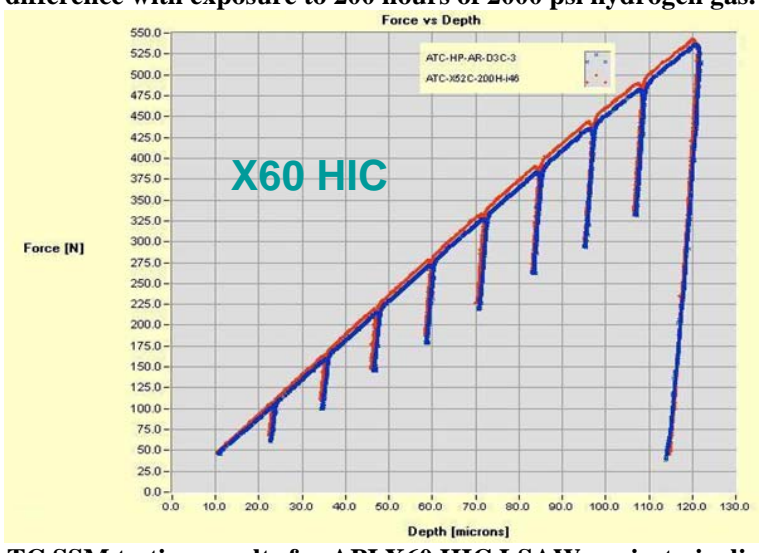

ATC SSM testing results for API X60 HIC LSAW project pipeline steel. Note that both the red and blue lines are basically on top of each either signifying that the test method did not see any difference with exposure to 200 hours of 2000 psi hydrogen gas.

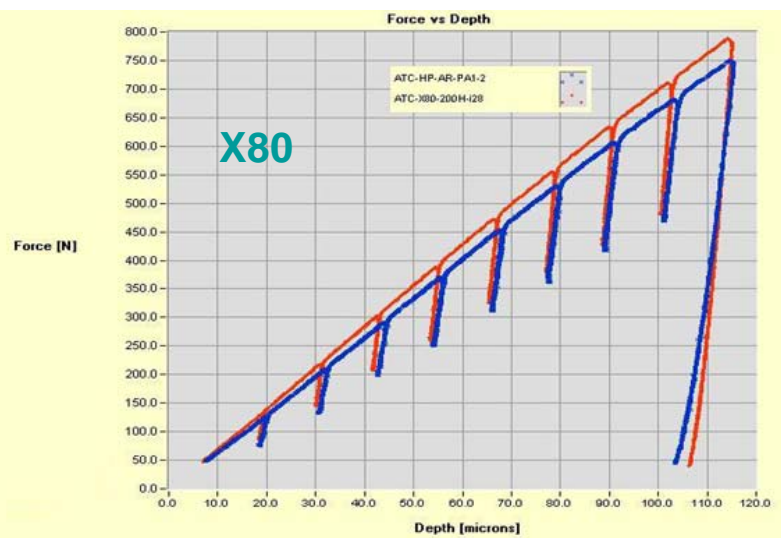

ATC SSM testing results for API X80 seamless non-project pipeline steel. Note that there is a separation between the red and blue lines signifying that the test method did see a difference with exposure to 200 hours of 2000 psi hydrogen gas.

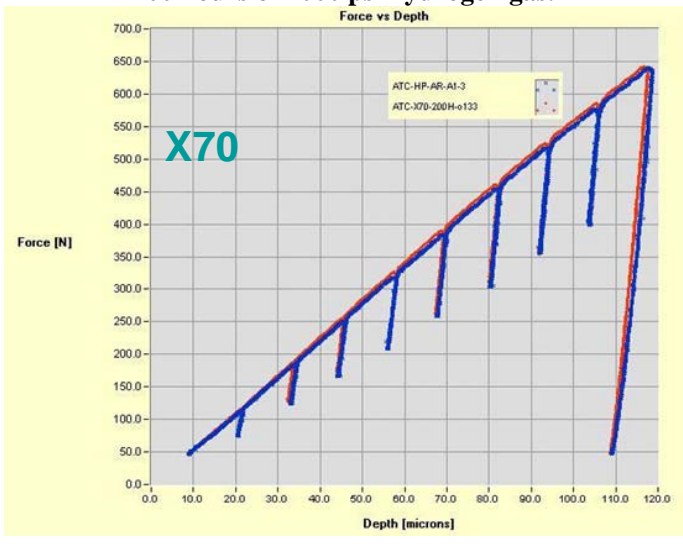

ATC SSM testing results for API X70 LSAW project pipeline steel. Note that both the red and blue lines are basically on top of each either signifying that the test method did not see any difference with exposure to 200 hours of 2000 psi hydrogen gas.

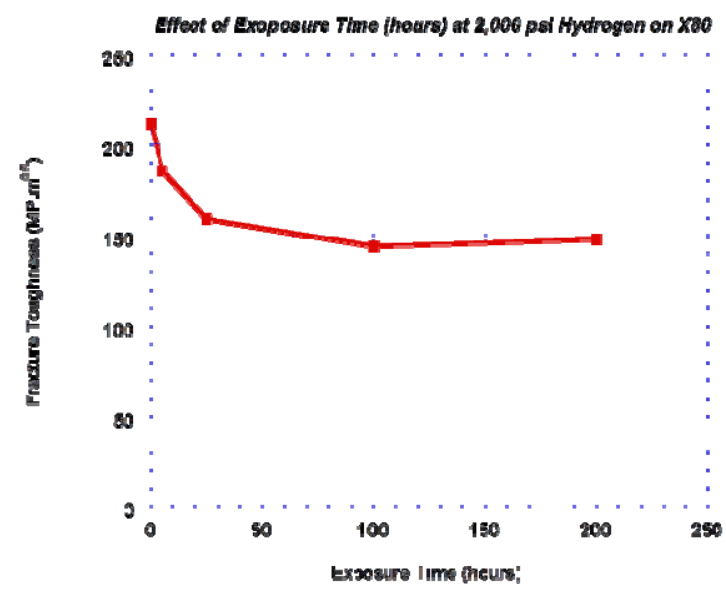

ATC SSM fracture toughness of API X80 seamless non-project pipeline steel results showing a $43 \%$ decrease in fracture toughness when exposed to hydrogen gas for 200 hours at 2000 psi hydrogen gas pressure.

Fig. 11 - ATC SSM Automated Ball Indentation test results in air and gaseous hydrogen for 200 hours at 2000 psi. Red lines represent air testing and blue lines represent gaseous hydrogen testing. 
Ex-situ hydrogen and helium testing was carried out with partner Sandia National Laboratory Livermore (SNLL) on project pipeline steel Alloy's A, B and C. Parameters of the ex-situ testing conducted at SNLL were as follows:

- Hydrogen testing parameters
o Pressure - 20, $000 \mathrm{psi}(138 \mathrm{MPa})$
o Temperature $-100 \mathrm{C}$
o Duration of the testing - 8 days
o Strain rate $-10^{-4} \mathrm{in} / \mathrm{in} / \mathrm{sec}$

- Helium testing parameters
o Pressure $-5000 \mathrm{psi}(34.5 \mathrm{MPa})$
o Temperature - $100 \mathrm{C}$
o Duration of the testing -8 days
o Strain rate $-10^{-4} \mathrm{in} / \mathrm{in} / \mathrm{sec}$

The results showed that microstructure did indeed have an effect on performance with project Alloy A showing instability in the stress-strain curve and project Alloy's B and C showing stable stress-strain curves, Figure 12.

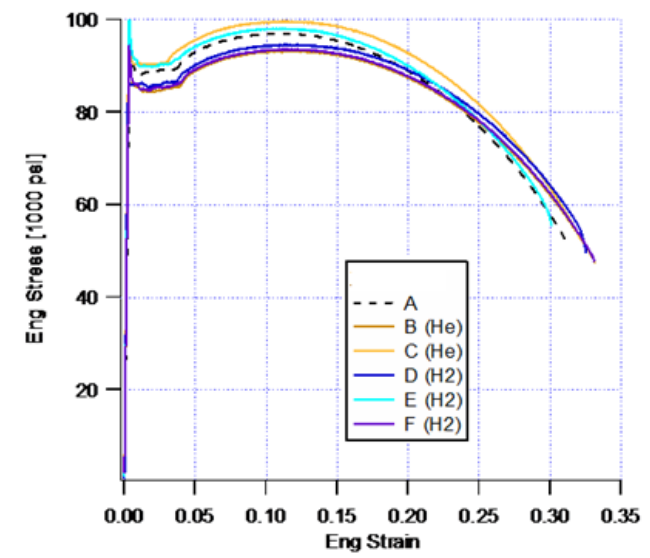

Project pipeline steel Alloy A, note the instability of the stress strain curve and degradation of strength with the exposure to hydrogen

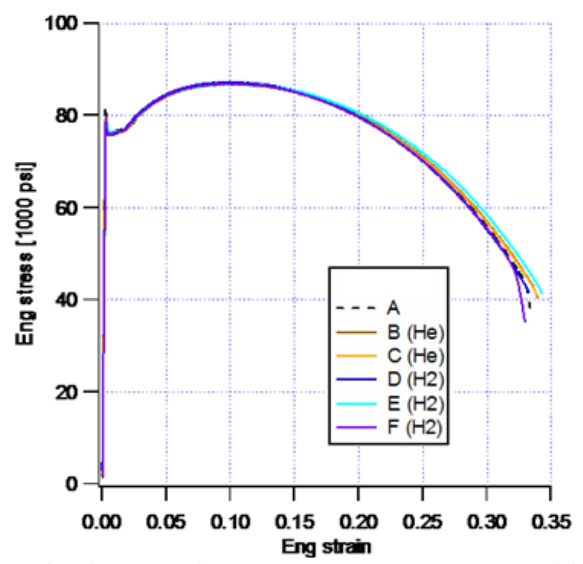

Project pipeline steel Alloy $B$, note the excellent stability of the stress strain curve and no degradation of strength with the exposure to hydrogen

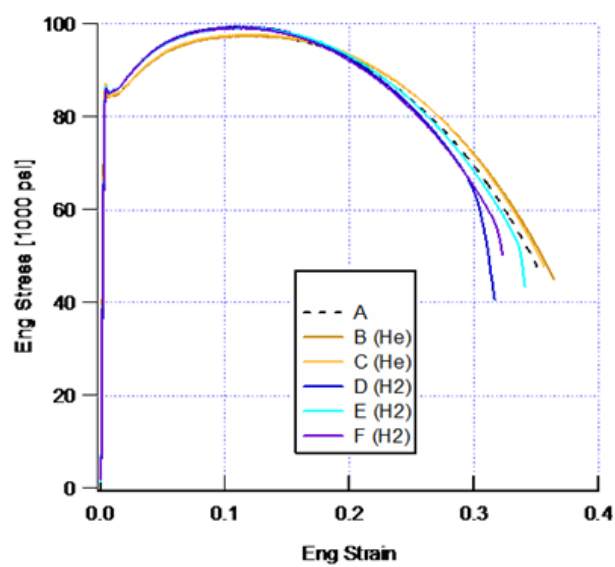

Project pipeline steel Alloy A, note the slight instability of the stress strain curve and slight degradation of strength with the exposure to hydrogen. This slight difference is most likely to the slight differences noted in microstructures between Alloy B and Alloy C.

Fig. 12 - Ex-situ hydrogen/helium testing conducted on project pipeline steel Alloy’s A, B and C at SNLL 
Standard NACE TM0284 Solution A (low pH) testing for resistance to hydrogen induced cracking of the four pipeline steels was conducted by industry partner EVRAZ Oregon Steel Mills. While this is a corrosive type HIC test and considered a more severe environment than a gaseous pressurized hydrogen environment absent of corrosion mechanism, it does give a relative idea of a given microstructure's resistant to hydrogen induced cracking. Regardless of how the hydrogen is introduced into the steel matrix, a microstructures ability to resist mechanical property degradation is the same. NACE TM0284 testing measures HIC resistance in the form of CLR (crack length ratio), CTR (crack thickness ratio) and CSR (crack sensitivity ratio). As expected the baseline Alloy A API X70 microstructure performed the worst in this type of testing. The other three pipeline steels (Alloy B, C and D) overall performed very well with mostly zero CLR, CTR and CSR results. The results of this testing strongly suggests that there would be microstructures that would have reasonable performance in a high pressure gaseous hydrogen environment.

ORNL developed standard round bar tensile testing capability in an autoclave vessel capable of testing in pressurized gaseous hydrogen up to 5000 psi, Figure 13.
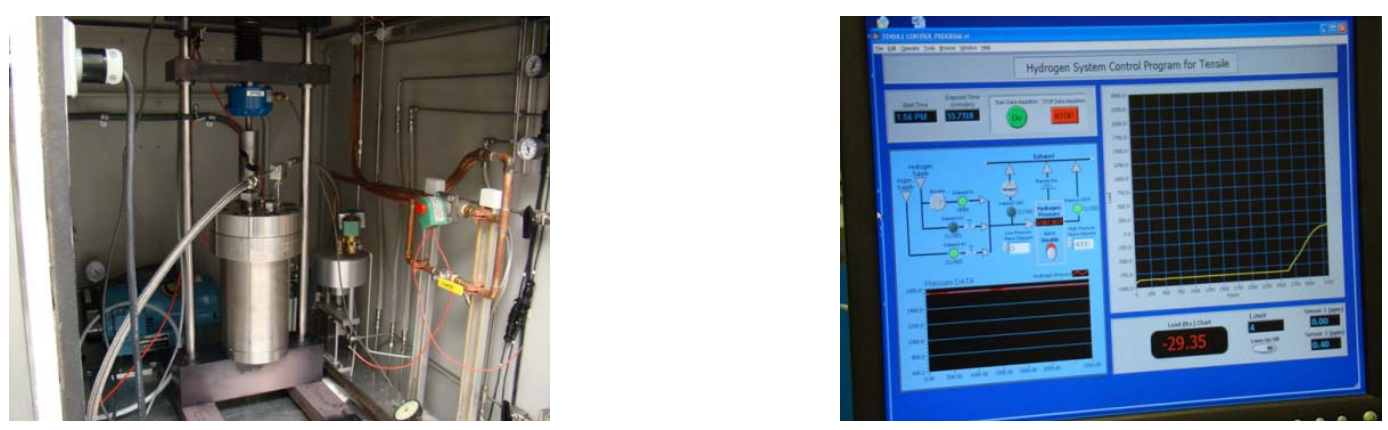

Fig. 13 - ORNL high pressure hydrogen tensile testing apparatus.

Using round bar tensile specimens, ORNL tested the four pipeline steels in air and then hydrogen pressures of $1600 \mathrm{psi}(11 \mathrm{MPa})$ and $3000 \mathrm{psi}(20.6 \mathrm{MPa})$. These two pressures were chosen based on input from the DOE Pipeline Working Group and partner ASME through the ASME B31.12 Hydrogen Piping and Pipeline Systems codes and standards committees as being reasonable and realistic potential operating pressures for hydrogen gas transmission. Initial testing at $1600 \mathrm{psi}$ in hydrogen and helium of project pipeline steels Alloy's A and C with different strain rates at ORNL showed that the presence of hydrogen had an effect on the fracture features of the tensile specimen along with decreasing the total strain required for complete failure, Figure 14. Alloy $\mathrm{C}$ seemed to perform slightly better than Alloy A in this first initial testing.

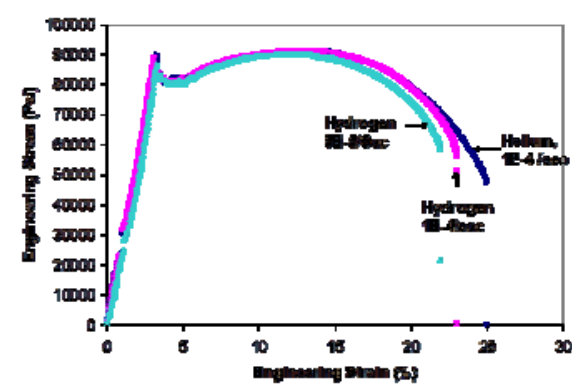

Project Alloy A API X70 pipeline steel tensile tested in hydrogen and helium at two different strain rates. Note that the presence of hydrogen decreases total strain needed for failure, regardless of strain rate.

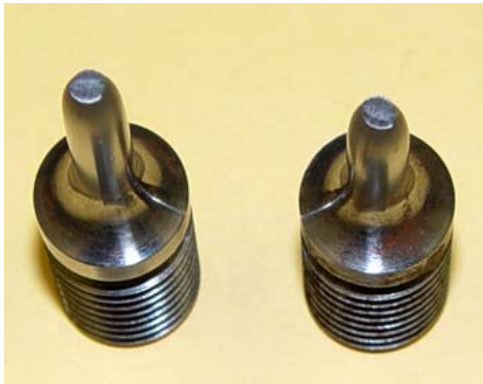

Helium Testing - Typical Ductile cup and cone fracture

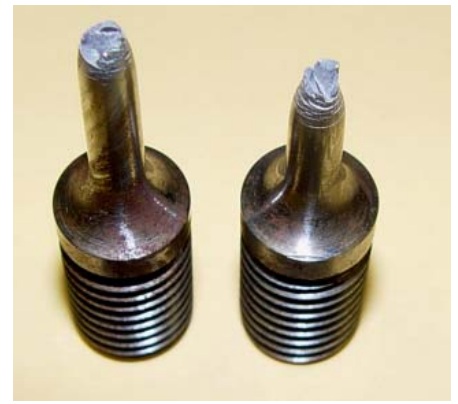

Hydrogen Testing - Faceted fracture surface with evidence for multiple secondary cracking 


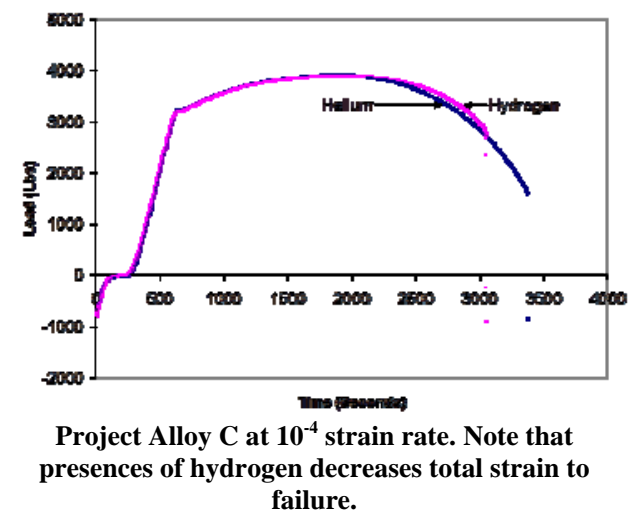

failure.

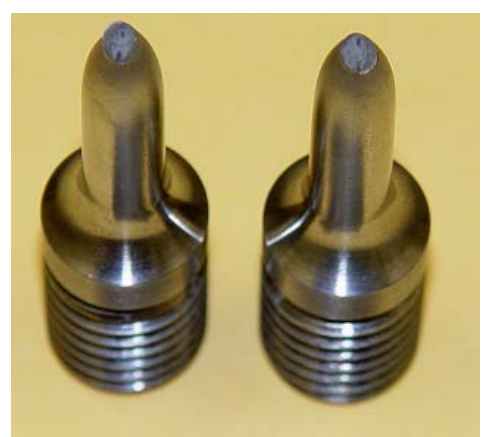

Helium Testing - Typical Ductile cup and cone fracture

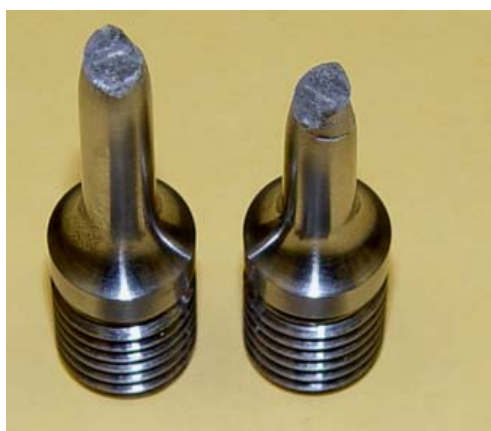

Hydrogen Testing - Faceted fracture surface with

evidence for multiple secondary cracking, does not seem as severe as in Alloy A

Fig. 14 - Project Alloy's A and C tensile tested at 1600 psi hydrogen and helium at ORNL

\section{Results - As-received Compositions, Mechanical Properties, Expected Microstructure and NACE TM0284 Testing}

The four pipeline steels represent typical API grades that would be used in commercial pipeline applications in the 1990's and 2000's. Alloy A is a typical API X70, C-Mn-Si-Nb-V alloy design produced by Thermomechanical Control Processing (TMCP) rolling finishing below the $\mathrm{Ar}_{3}$ followed by air cooling. Alloy's B and C are a current X80 type alloy design used around the world utilizing an alloy design of $\mathrm{C}-\mathrm{Mn}-\mathrm{Si}-\mathrm{Nb}(0.080-0.10 \% \mathrm{Nb})$ produced by TMCP rolling finishing above the $\mathrm{Ar}_{3}$ followed by ACC (water) cooling. Alloy D is a low C-Mn-Si-Nb API X60 HIC designed for low pH sour service natural gas applications where resistance to hydrogen induced cracking in a NACE TM0284 low pH (Solution A) environment is expected. Alloy D was produced by TMCP rolling finishing at approximately the $\mathrm{Ar}_{3}$ followed by air cooling. As noted in Table 2, Alloy A is considered a baseline grade as it is very common alloy design that has been used extensively in the past years for oil and gas transmission pipeline infrastructure. Details of the chemistry of the four as-received pipeline steels can be found in previous Table 3.

The as-received mechanical properties as reported by the mill producer of the four pipeline alloys can be found in Table 4.

Table 4: As-received Mechanical Properties of Four Pipeline Steels in the Project

\begin{tabular}{|c|c|c|c|c|}
\hline Alloy & $\begin{array}{c}\text { YS } \\
\text { (MPa) }\end{array}$ & $\begin{array}{c}\text { TS } \\
\text { (MPa) }\end{array}$ & $\begin{array}{c}\text { \%Elongation } \\
\mathbf{5 0} \mathbf{~ m m}\end{array}$ & YT Ratio \\
\hline A & 565 & 606 & 40 & 0.93 \\
\hline B & 541 & 596 & 40 & 0.91 \\
\hline C & 545 & 648 & 45 & 0.84 \\
\hline D & 435 & 486 & 42 & 0.90 \\
\hline
\end{tabular}

It should be noted that all of the samples came from plate or coil (skelp) that was destined for pipe production. The as-received strength reported is based on the expected skelp to pipe strength shifts that typically occur. Hence, Alloy A which was destined for X70 has plate YS high enough to account for the expected shift downward in YS during pipe production. In addition, Alloy's B and C were destined for X80 pipe and hence have slightly lower YS to account for an expected upward shift in YS during pipe production. 
The expected microstructures of the four as-received alloy designs based on the composition and rolling design were as follows:
Alloy A - Ferrite/Pearlite (F/P)
Alloy B, C, D - Ferrite/Fine Acicular Ferrite (F/FAF*)
*Fine acicular ferrite is low carbon bainitic structure.

Microstructural characterization, which will be presented later, showed that there were differences between the actual microstructures and that expected for some of the alloys. Even though there were differences between the actual vs. expected microstructures for some of the alloys, these microstructures are valid for what might be produced in a steel production environment.

To gain a baseline understanding of the performance of the four alloys/microstructures in the presence of hydrogen, all four were tested in the NACE TM0284 ${ }^{8}$ low $\mathrm{pH}$ (Solution A) environment. Granted that this is a corrosion test and probably more severe than that of a gaseous hydrogen environment, once the hydrogen enters the steel matrix the performance of each microstructure in the presence of hydrogen can be compared relative to each other. The results of the NACE testing can be found in Table $5^{9}$.

Table 5: Results of NACE TM0284 Low pH (Solution A) Testing of Selected Alloys

\begin{tabular}{|c|c|c|c|}
\hline Alloy & CLR \% & CSR \% & CTR \% \\
\hline A & $11.8^{\mathrm{a}}$ & 0 & 0.1 \\
\hline B & $0.4^{\mathrm{b}}$ & 0 & 0 \\
\hline C & 0 & 0 & 0 \\
\hline D & 0 & 0 & 0 \\
\hline
\end{tabular}

a) Cracks located at ferrite/pearlite interface

b) Cracks located between surface and $1 / 4$ thickness and associated with cluster of non-metallic inclusions (related to $1 / 4$ thickness casting inclusion issue)

Overall, the results for each of the alloys in this corrosive environment performed as expected. Alloy A performed the worst of the four and the remaining three alloys performed about the same. If Alloy B did not have the cluster of non-metallic inclusions, its performance would have been the same as Alloys C and D. Non-metallic inclusions can act as traps for hydrogen and cause hydrogen induced cracking.

\section{Microstructural Characterization}

Microstructure plays a role in a given steel's ability to perform in the presence of hydrogen. Since the objective of this project was to identify steel compositions/microstructures that might be suitable for the transport of gaseous hydrogen under pressure, volume fraction of the microstructural phases for each alloy was determined. Optical microscopy, scanning electron microscopy (SEM), and transmission electron microscopy (TEM) techniques were used to identify major microstructural phases and to estimate the volume fraction of each phase.

Alloy A, a standard API X70, C-Mn-Si-Nb-V alloy design, was characterized as approximately $92 \%$ polygonal ferrite and $8 \%$ upper bainite ${ }^{10}$. Optical microscopy, SEM and TEM analysis can be seen in Figures 15, 16 and 17, respectively. Under the optical microscope, the upper bainite appears dark, as it has low reflectivity. At higher magnifications under SEM and TEM examination, upper bainite will exhibit a "feather-like" arrangement (Figure 16 and 17) of its ferrite laths in contrast to the sheaves of approximately parallel laths that one observes in pearlite or lath martensite. 

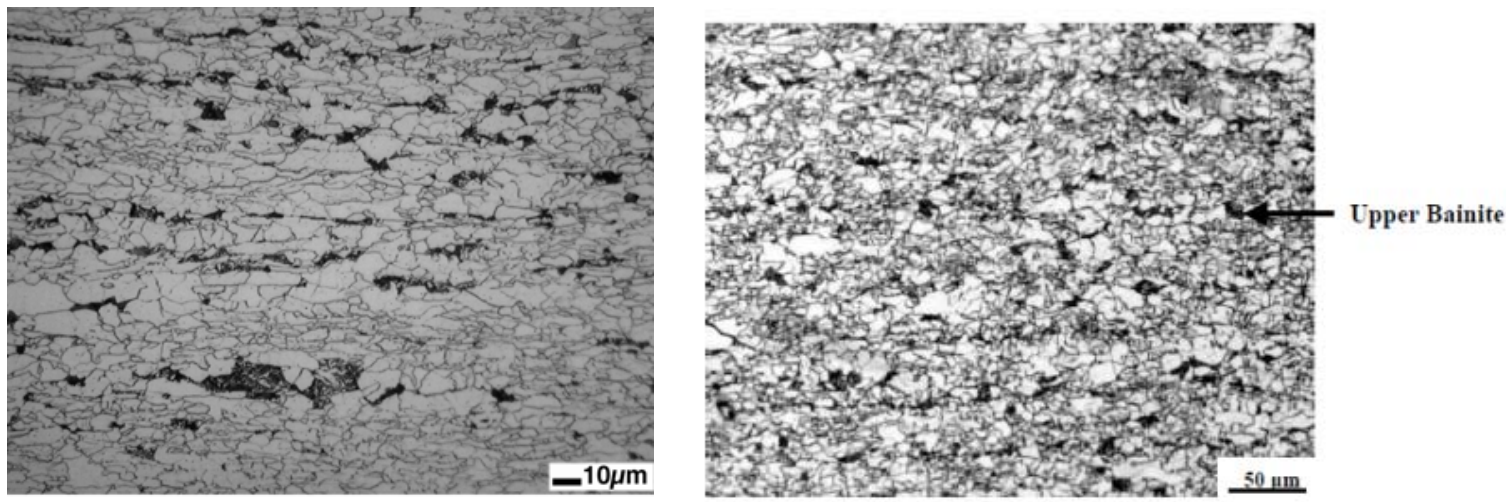

Dark Islands Identified as Upper Bainite

Fig. 15 - Optical microscopy characterization of Alloy A
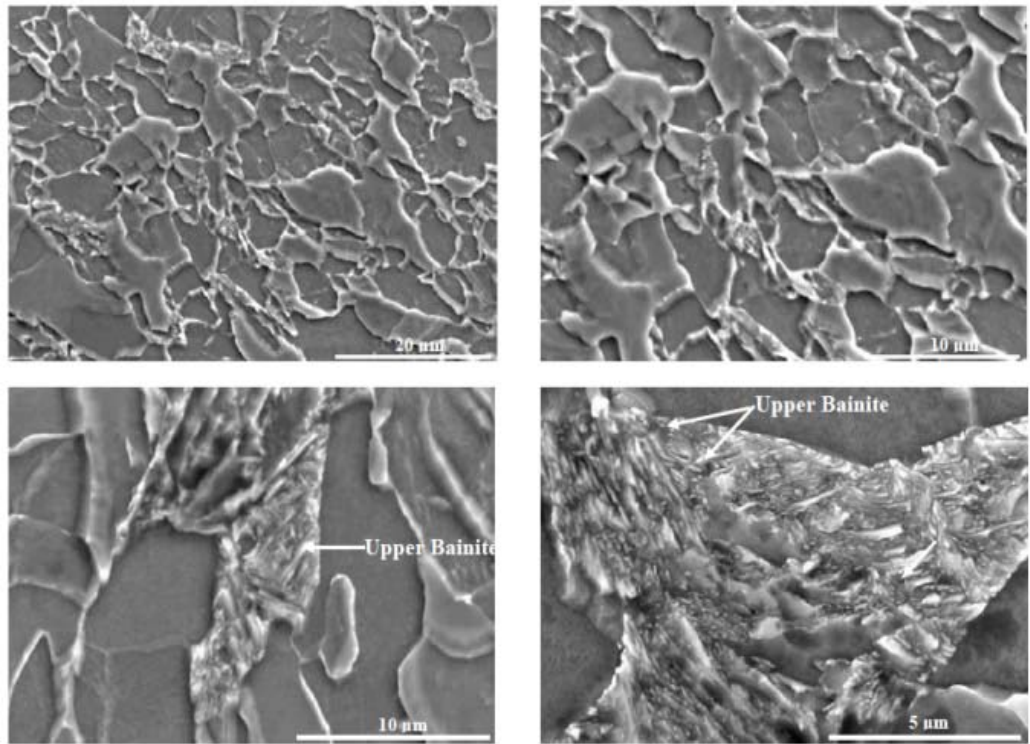

Fig. 16- SEM analysis characterization of Alloy A
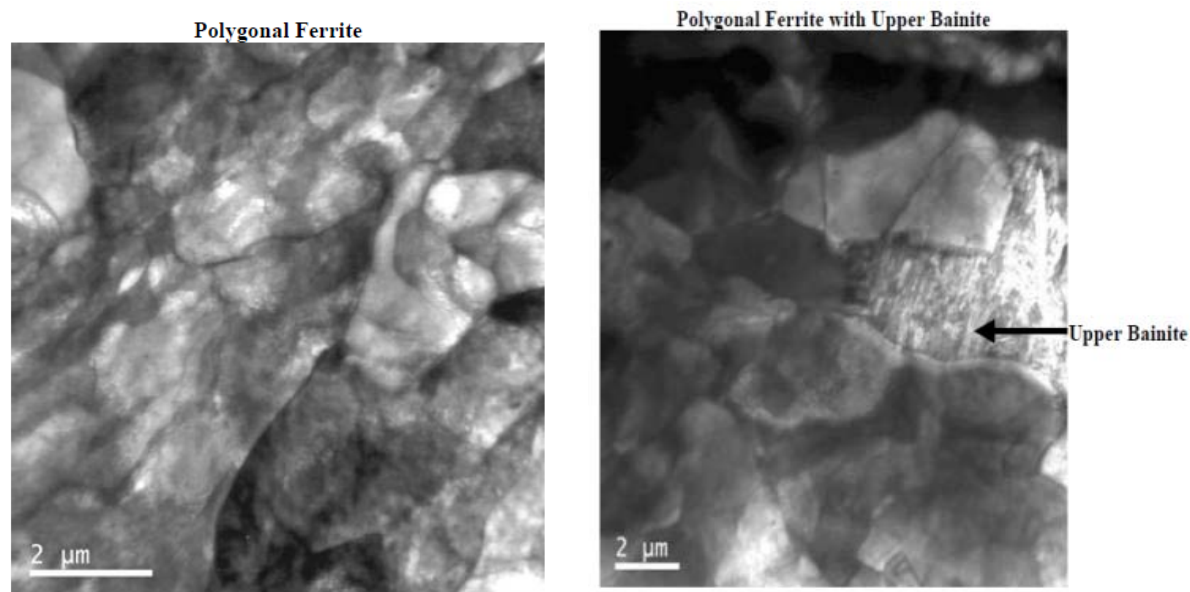

Fig. 17 - TEM analysis characterization of Alloy A 
Alloy B, a standard API X80 (C-Mn-Si-Nb) alloy design, was characterized as approximately 90\% polygonal ferrite and $10 \%$ coarse acicular ferrite. The acicular ferrite was only $10 \%$ by volume fraction and coarse, which was somewhat different than what was originally expected. Optical microscopy, SEM and TEM analysis can be seen in Figures 18, 19 and 20 respectively.
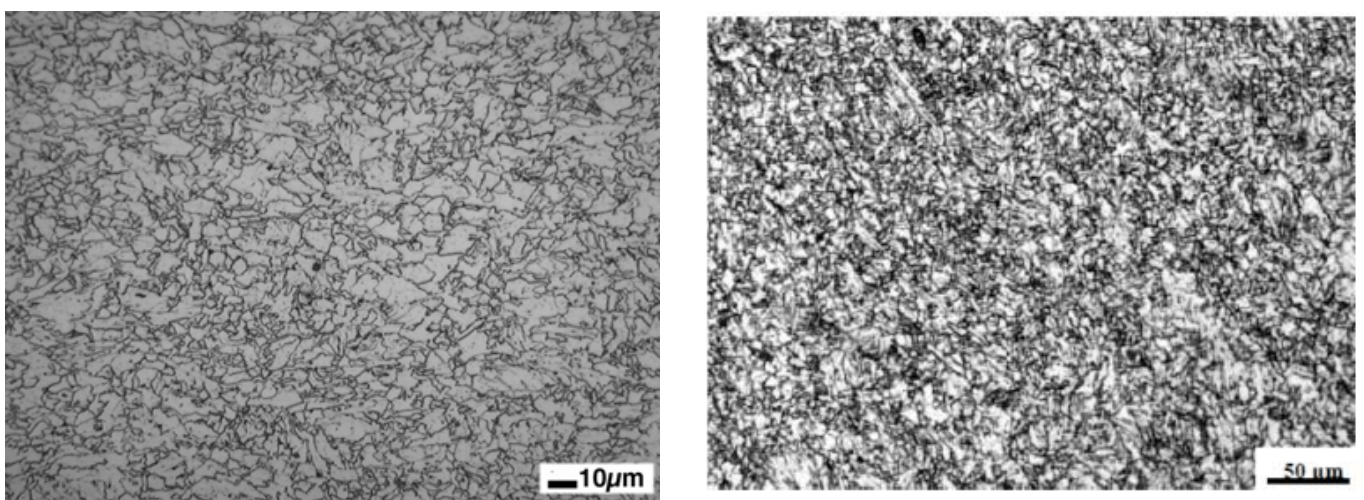

Polygonal ferrite and coarse acicular ferrite

Fig. 18 - Optical microscopy characterization of Alloy B
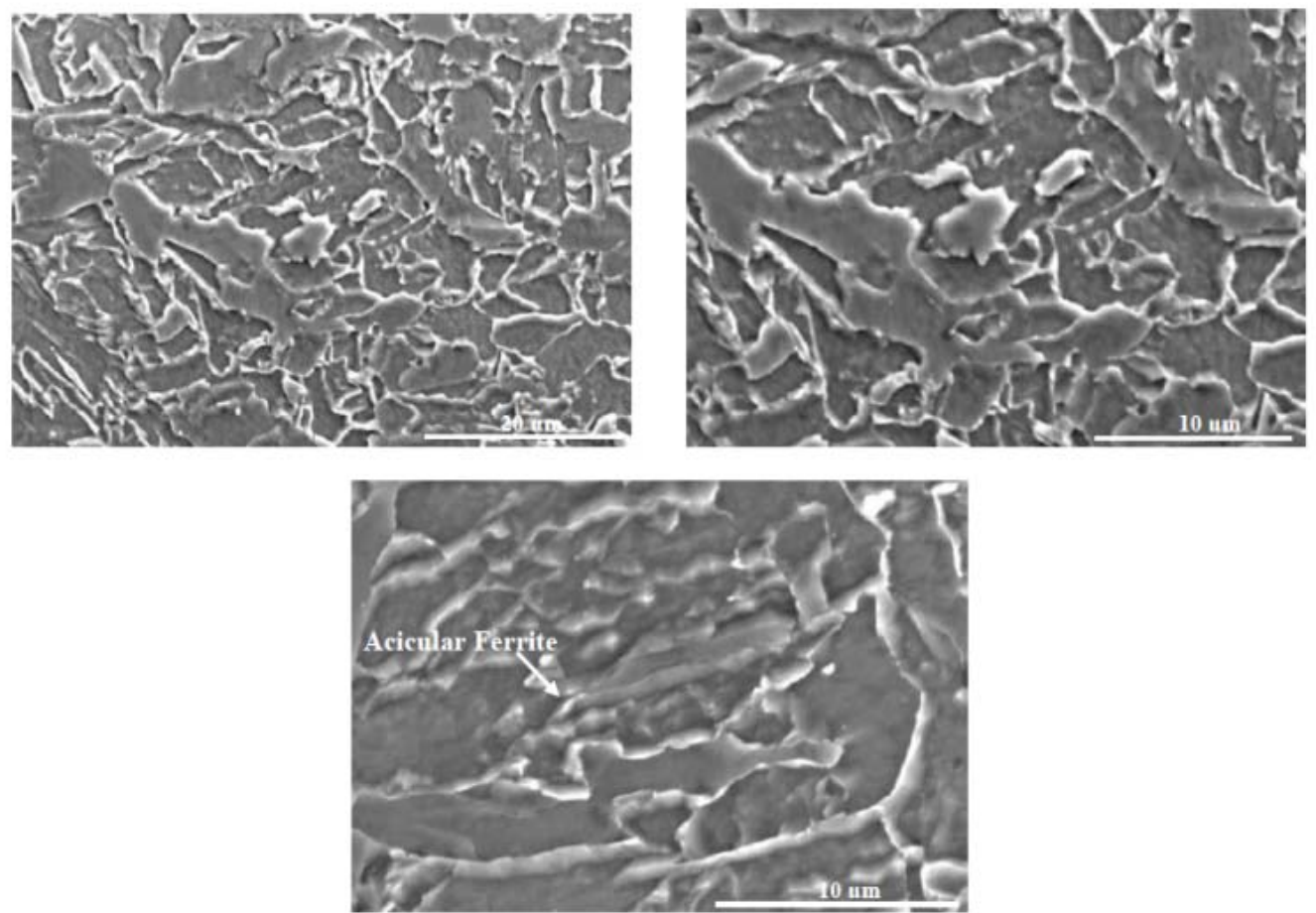

Coarse Acicular Ferrite is more apparent in TEM micrographs

Fig. 19 - SEM analysis characterization of Alloy B 

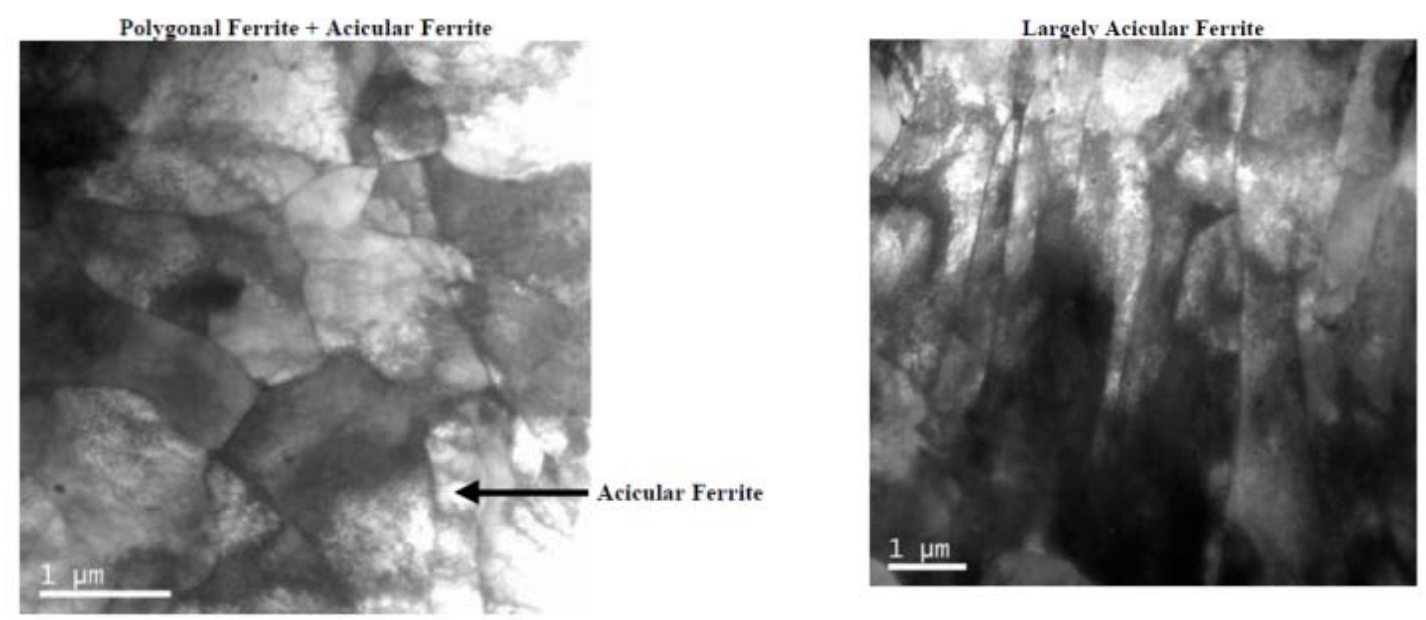

Fig. 20 - TEM analysis characterization of Alloy B

Alloy C, a standard API X80 alloy design ((C-Mn-Si-Nb) with more solute elements than Alloy B) was characterized as approximately $90 \%$ polygonal ferrite and $10 \%$ predominately coarse acicular ferrite, but with very small amount of upper bainite. The acicular ferrite with a very small amount of upper bainite was only $10 \%$ by volume fraction and coarse, which again was somewhat different than what was originally expected. Optical microscopy, SEM and TEM analysis can be seen in Figures 21, 22 and 23, respectively. The upper bainite has been delineated in optical light, SEM and TEM microscopy. The dark appearance of upper bainite is characterized in the light microscope. Due to the low carbon level of $0.04 \% \mathrm{C}$ in Alloy $\mathrm{C}$, the upper bainite is lathe ferrite with very limited carbon precipitation between the laths.
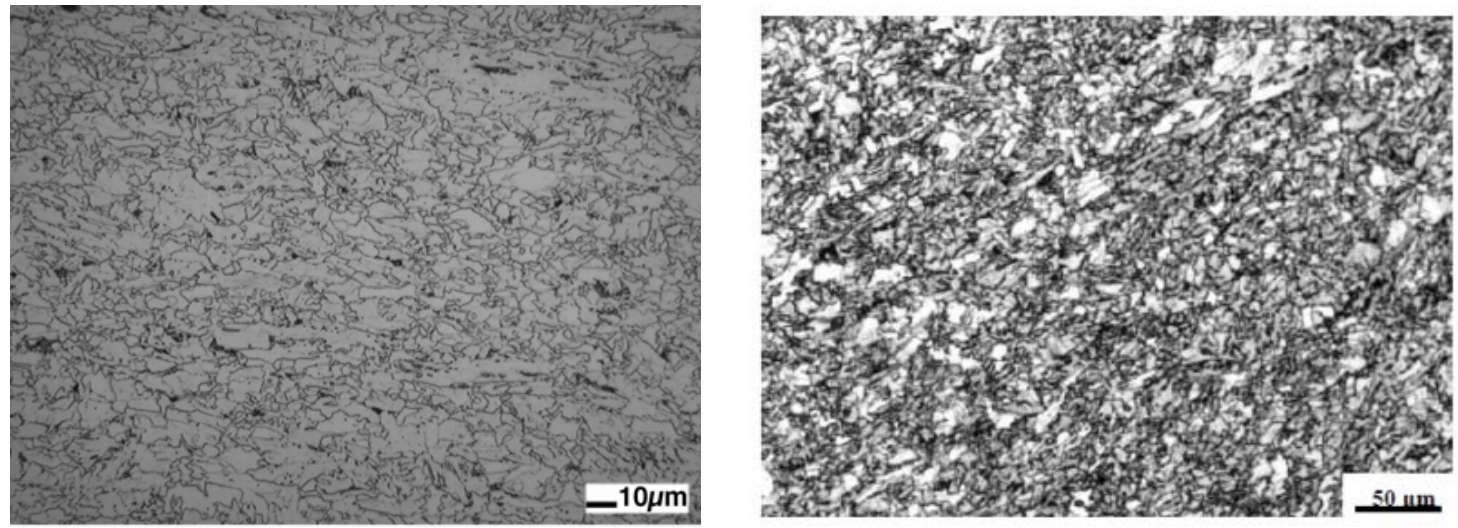

Dark Islands Identified as Upper Bainite

Fig. 21 - Optical microscopy characterization of Alloy C 

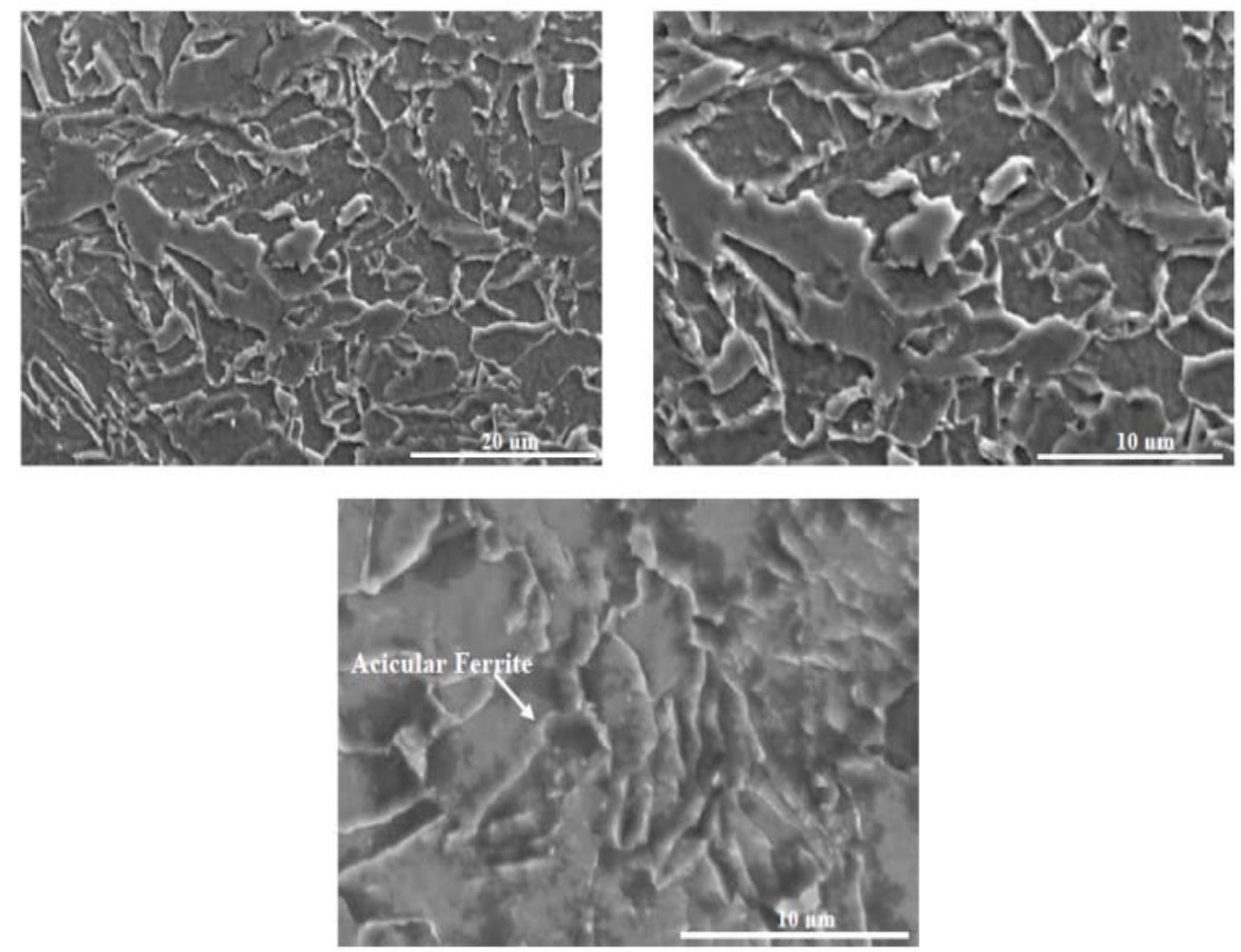

Coarse Acicular Ferrite is more apparent in TEM micrographs

Fig. 22 - SEM analysis characterization of Alloy C
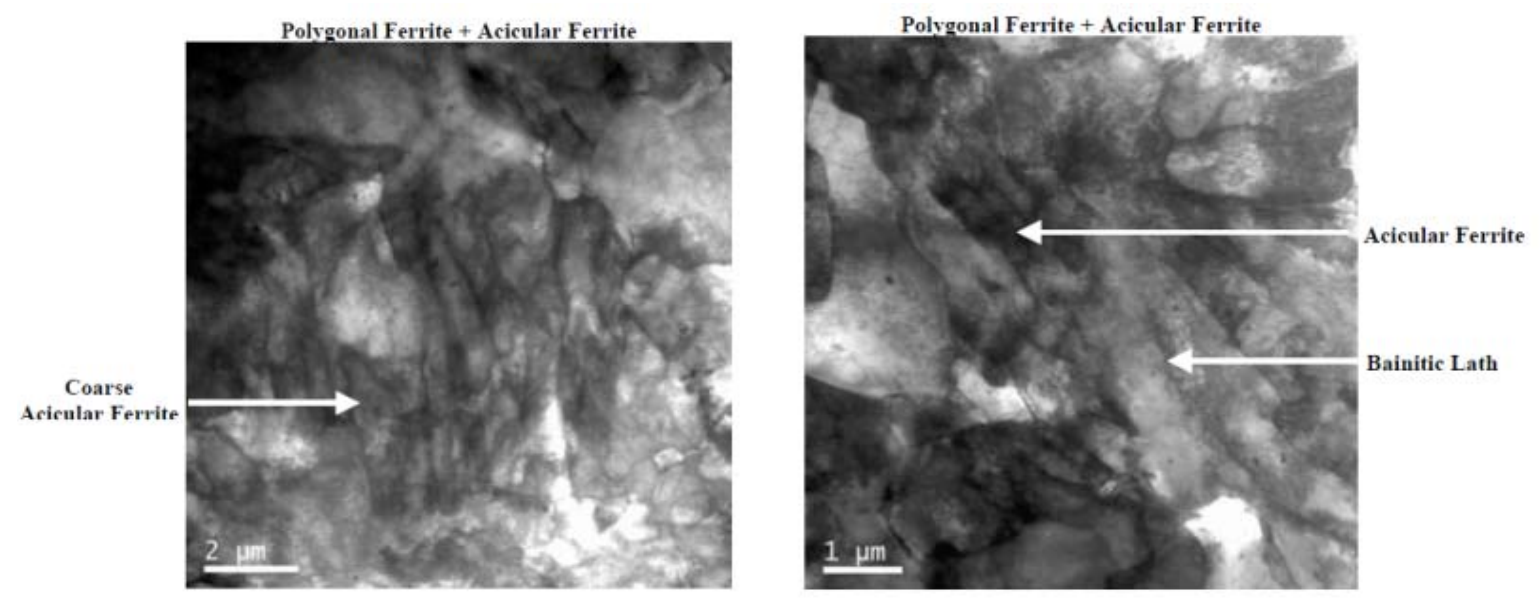

Fig. 23 - TEM analysis characterization of Alloy C

Alloy D, an API X60 HIC design for low pH sour service natural gas applications (low C-Mn-Si-Nb), was characterized as $100 \%$ polygonal ferrite, which was somewhat different than originally expected. Optical microscopy, SEM and TEM analysis can be seen in Figures 24, 25 and 26, respectively. 

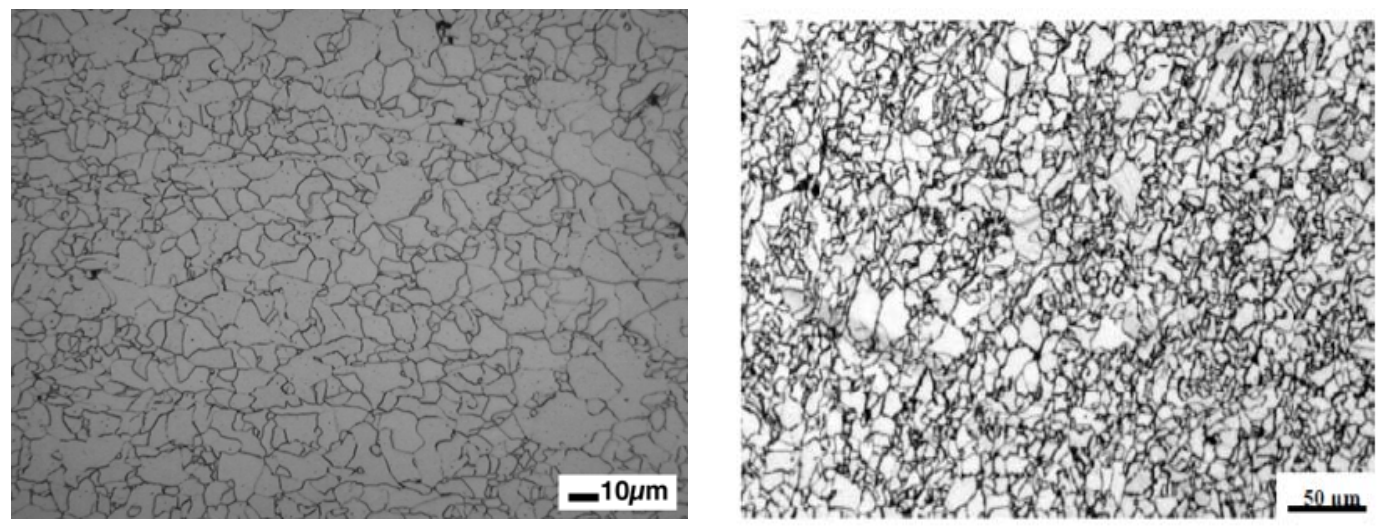

Fig. 24 - Optical microscopy characterization of Alloy D
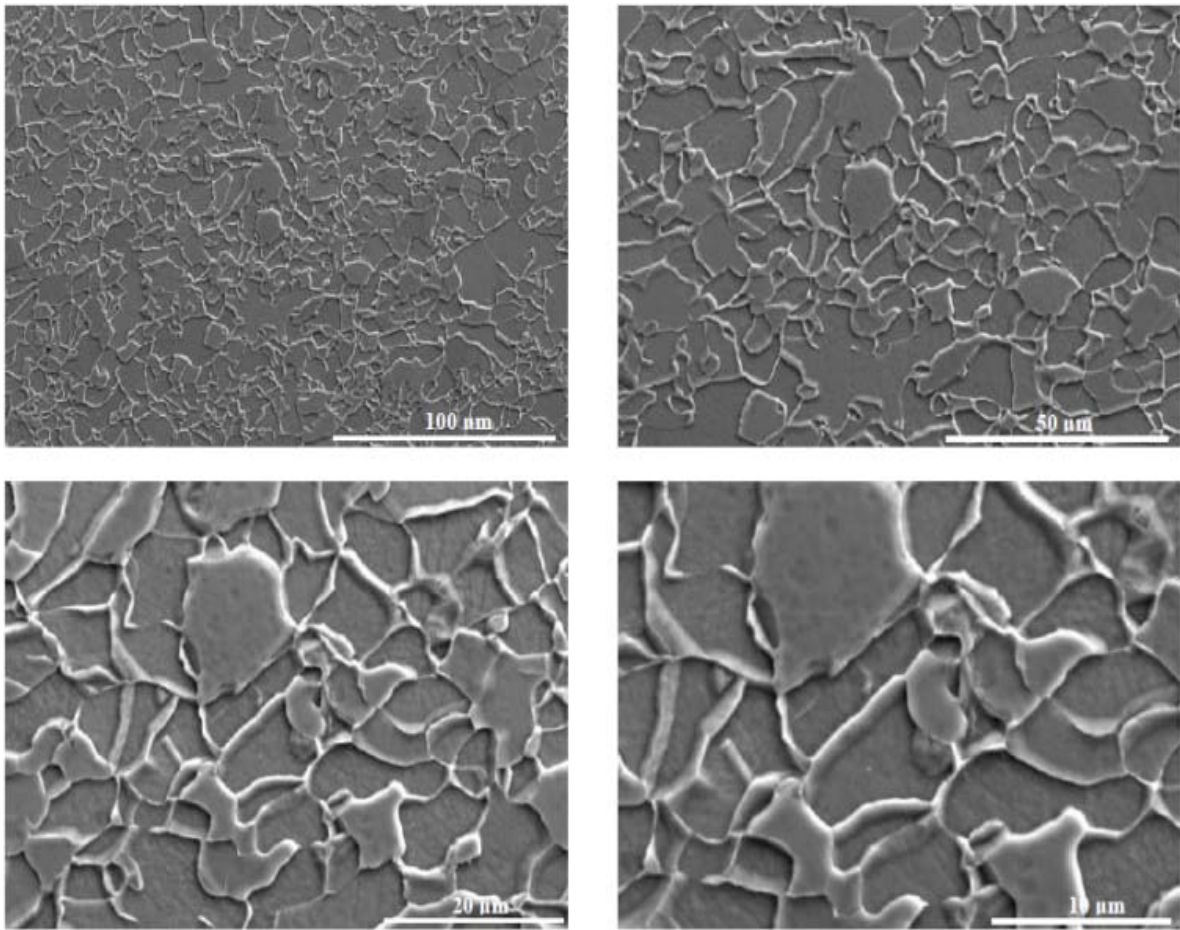

Fig. 25 - SEM analysis characterization of Alloy D
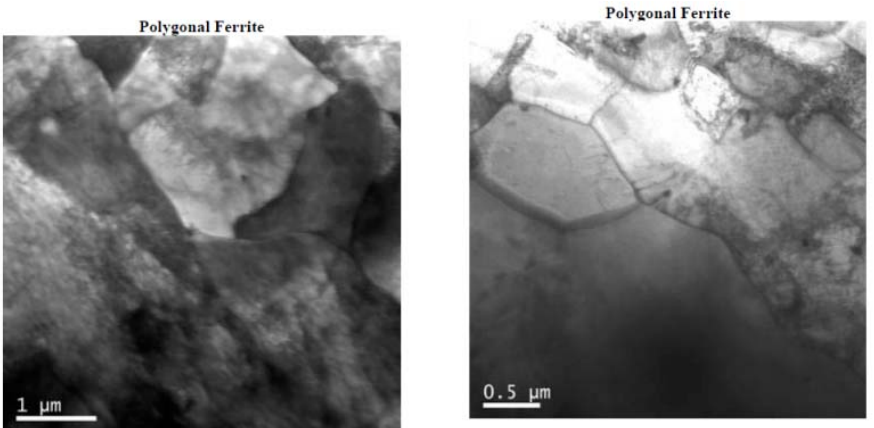

Fig. 26 - TEM analysis characterization of Alloy D 
Even though non-pipeline steel Alloy's E and F were not slated for further evaluation in the project, microstructural characterization was completed on them for future reference.

Alloy $\mathrm{E}$ was a low $\mathrm{C}$, high $\mathrm{Mn}, \mathrm{Ni}, \mathrm{B}$ and $\mathrm{Nb}$ microalloyed steel produced by Thermo-Mechanical Control Processing (TMCP) rolling followed by accelerated water cooling (ACC) generating a minimum of $100 \mathrm{ksi}(690 \mathrm{MPa})$ yield strength intended for structural applications such as crane booms. The microstructure was characterized as 100\% acicular ferrite. SEM and TEM analysis can be seen in Figures 27 and 28.

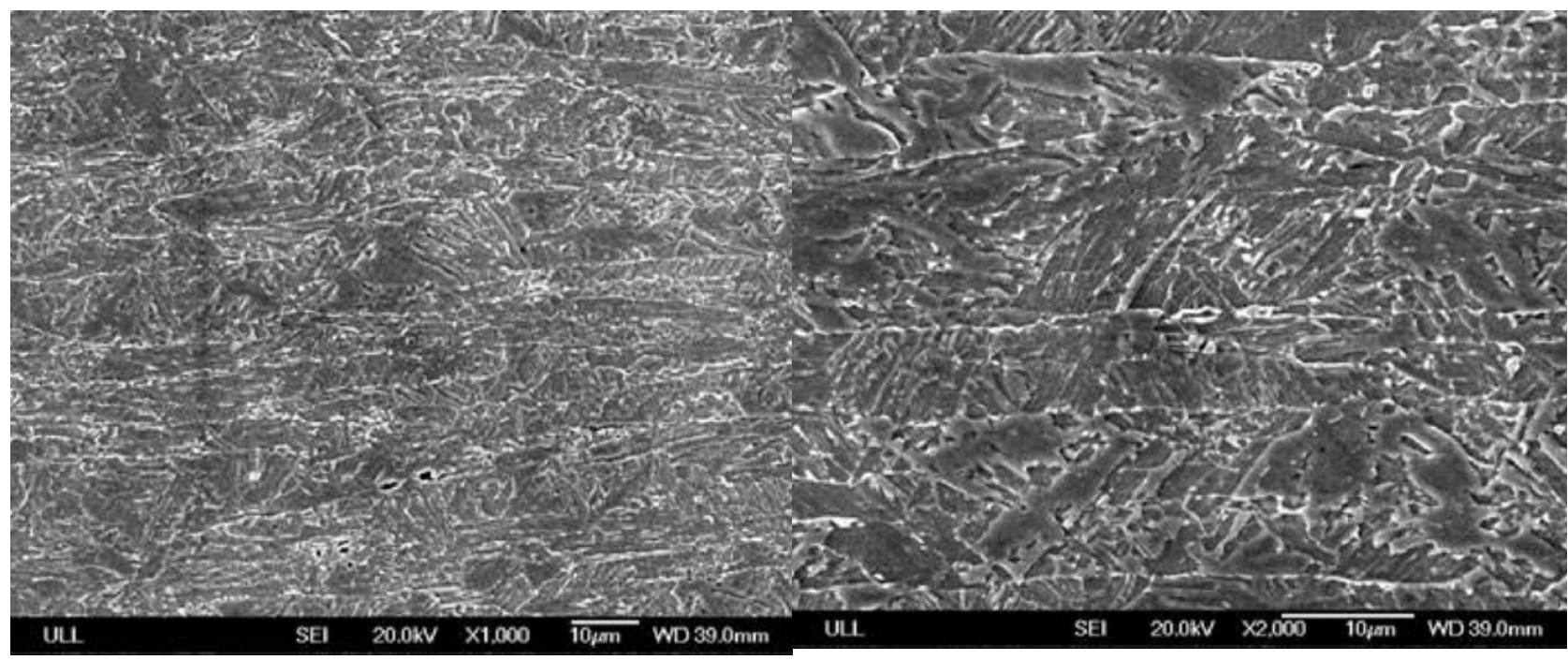

Fig. 27 - SEM analysis characterization of Alloy E
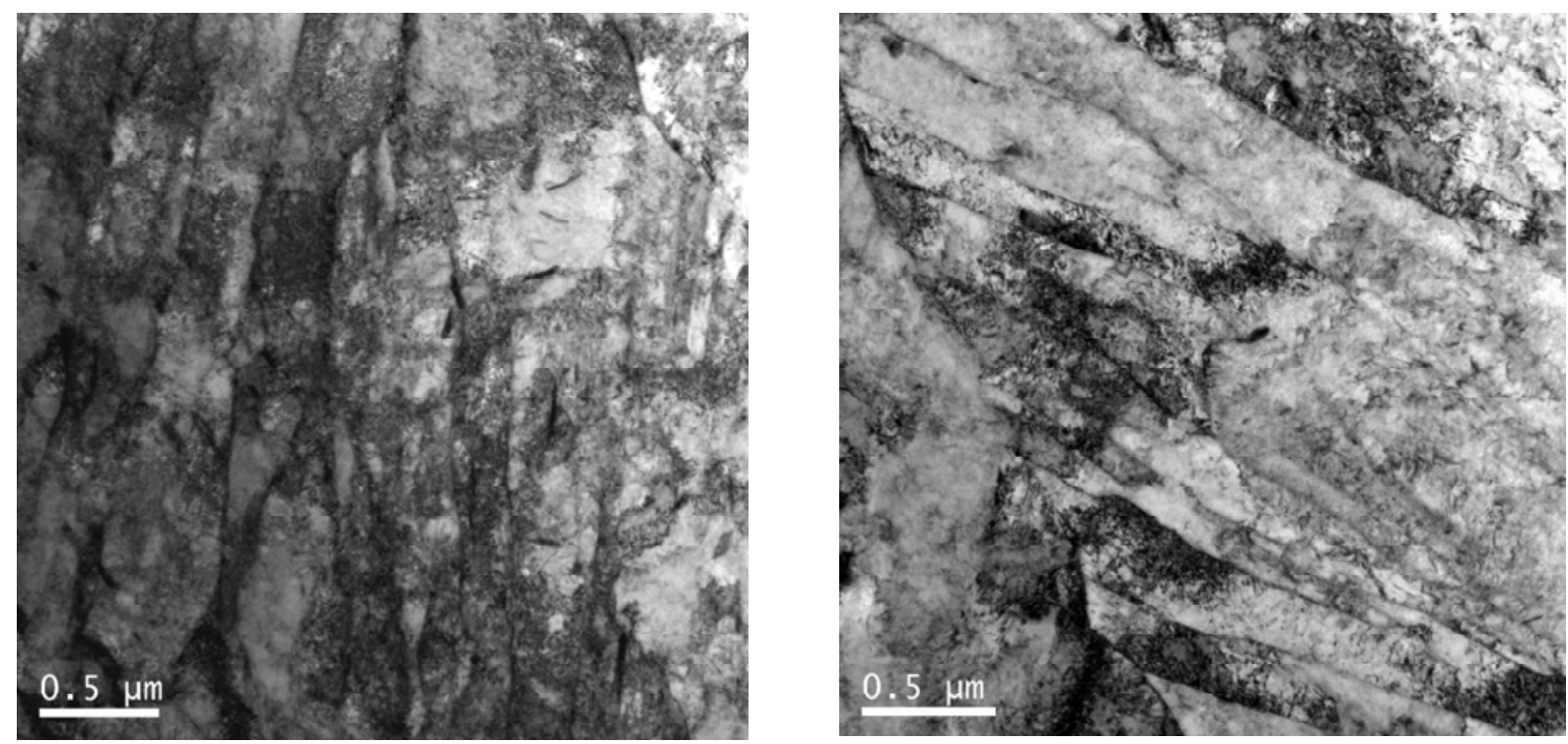

Fig. 28 - TEM analysis characterization of Alloy E

Alloy $\mathrm{F}$ was a medium $\mathrm{C}$, high $\mathrm{Mn}, \mathrm{Mo}, \mathrm{Cr}, \mathrm{B}$ and $\mathrm{Nb}$ microalloyed steel produced by austenitizing (heat treatment) followed by water quenching and subsequent furnace tempering (Q\&T) generating a minimum of $400 \mathrm{BHN}$ hardness intended for abrasion resistant structural applications such as concrete trucks, dump 
trucks, etc. The microstructure was characterized as $80 \%$ acicular ferrite plus $20 \%$ lath-type bainite. SEM and TEM analysis can be seen in Figures 29 and 30.

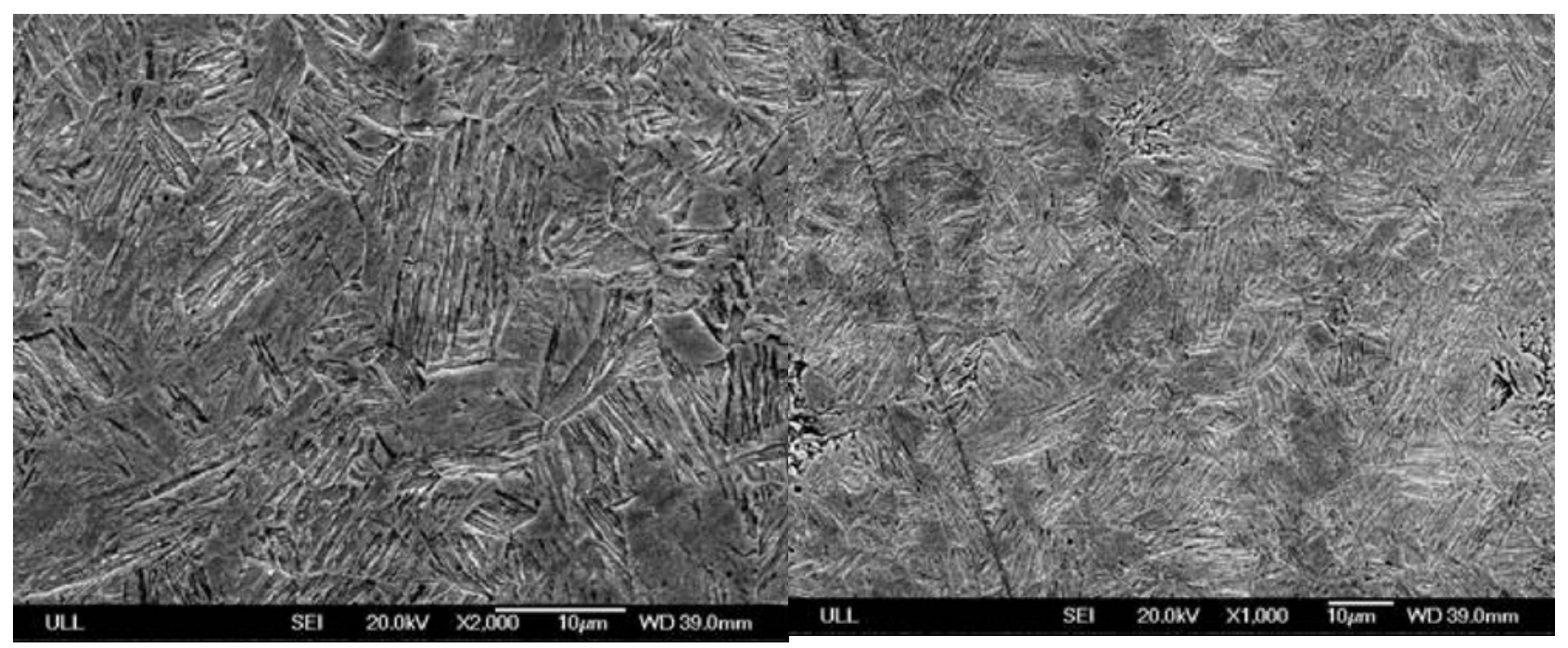

Fig. 29 - SEM analysis characterization of Alloy F
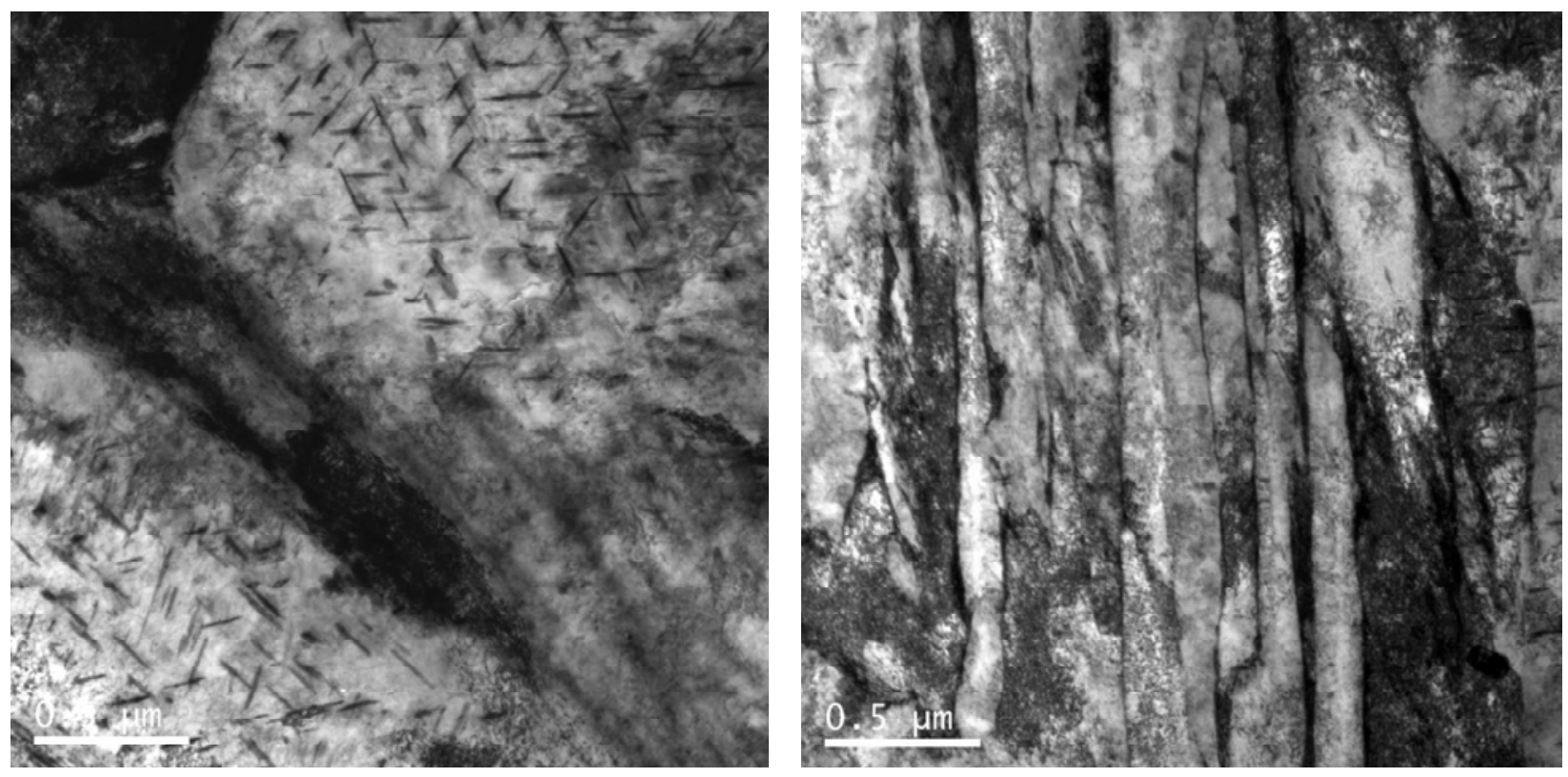

Fig. 30 - TEM analysis characterization of Alloy $\mathbf{F}$

\section{Tensile Test Results in Hydrogen}

Tensile testing in the presence of helium and hydrogen gas was performed at Oak Ridge National Laboratory in Oak Ridge, TN. Helium was used and tested at all pressures as the baseline for comparison. Pressures of 5.5 MPa (800 psi), $11 \mathrm{MPa}(1600 \mathrm{psi})$ and $20.7 \mathrm{MPa}(3000 \mathrm{psi})$, representing potential operating pressures of a hydrogen gas transmission pipeline, were used. Two strain rates $\left(10^{-4}\right.$ and $\left.10^{-5}\right)$ were explored. In all 48, tensile tests were performed in the presence of helium and hydrogen. Reduction in area (RA), a measure of the tensile ductility of metals, was reduced by testing in gaseous hydrogen. 
Thus, it is used as a metric for the effects of gaseous hydrogen during tensile testing, as shown for the 5.5 $\mathrm{MPa}$ (800 psi) testing of Alloy A in Figure 31.

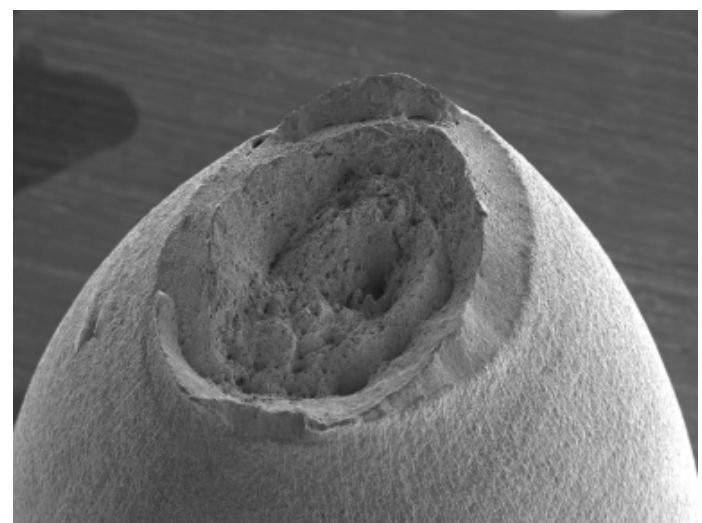

$5.5 \mathrm{MPa}(800 \mathrm{psi}) \mathrm{He}$, $1 \times 10^{-4} / \mathrm{sec}, 78 \% \mathrm{RA}$ with a standard "cup and cone" fracture feature and good "necking” showing good ductility.

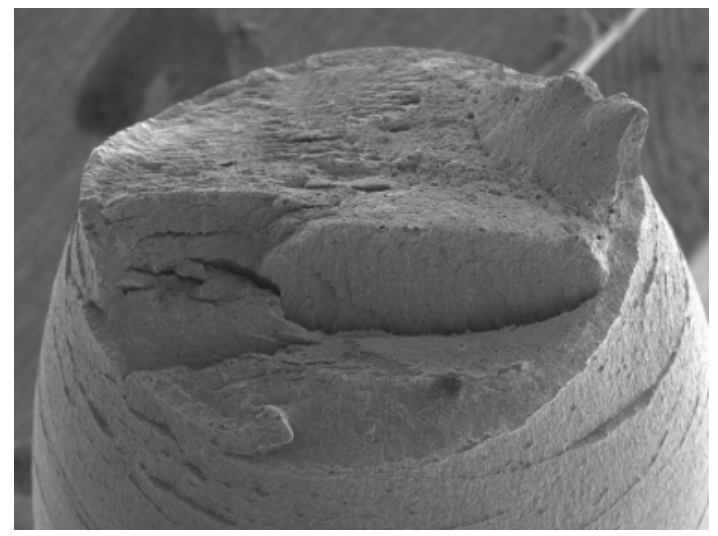

5.5 MPa (800 psi) $\mathrm{H}_{2}$, $1 \times 10^{-4} / \mathrm{sec}, 42 \% \mathrm{RA}$ with reduced "necking" and poorer ductility.

Fig. 31 - Helium vs. hydrogen testing of alloy A at 5.5 MPa (800 psi) showing loss of ductility

The results of the testing are provided in Figures $\mathbf{3 2}$ and $\mathbf{3 3}$ for the two strain rates, respectively. For both strain rates, the reduction in area in helium is close to $80 \%$ or greater, which is expected for these steels. At $5.5 \mathrm{MPa}(800 \mathrm{psi})$ for both strain rates, the tensile ductility (RA) is significantly reduced for all alloys, although some alloys/microstructures perform slightly better. Beyond $5.5 \mathrm{MPa}(800 \mathrm{psi})$, even though there is some variability in the data, especially at the $10^{-4}$ strain rate, a trend of no significant further reduction in tensile ductility. This demonstrates that volume fractions of phases affects the performance in gaseous hydrogen. This becomes more pronounced as the pressure is increased up to $20.7 \mathrm{MPa}$ (3000 psi).

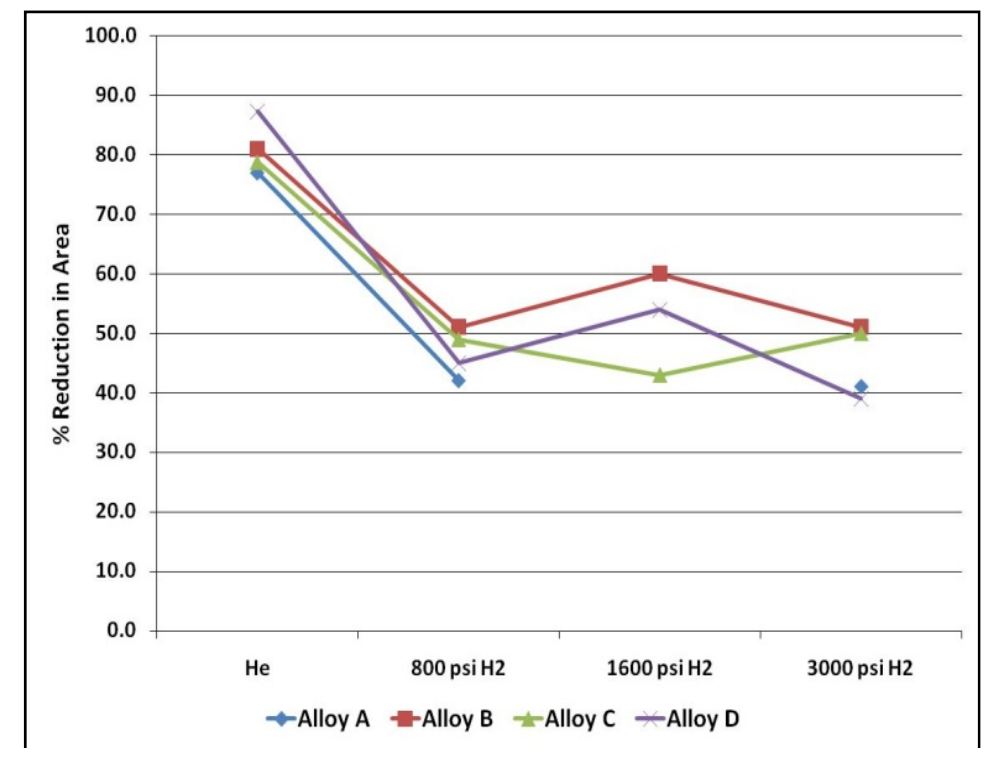

Fig. 32 - \% Reduction in area comparison at strain rate of $10^{-4}$ for helium and hydrogen tensile testing at pressure 


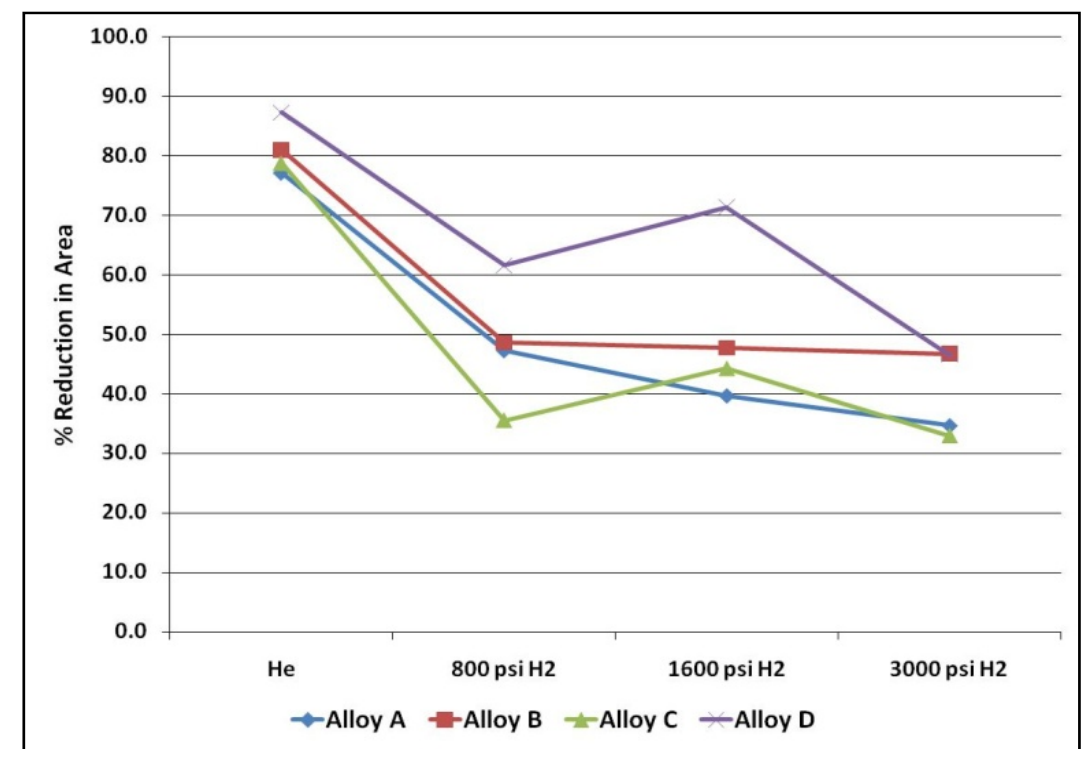

Fig. 33 - \% Reduction in area comparison at strain rate of $10^{-5}$ for helium and hydrogen tensile testing at pressure

In this testing, the two microstructures that were devoid of any upper bainite, Alloys B and D, in general performed better at each strain rate with increasing hydrogen pressure. In fact, the tensile ductility of Alloy B is relatively insensitive to the hydrogen pressure and is approximately $50 \%$ for all three pressures.

The YS and TS were not altered in the presence of hydrogen. Only the fracture stress showed variability in hydrogen. This is illustrated for Alloy B in Figure 34.

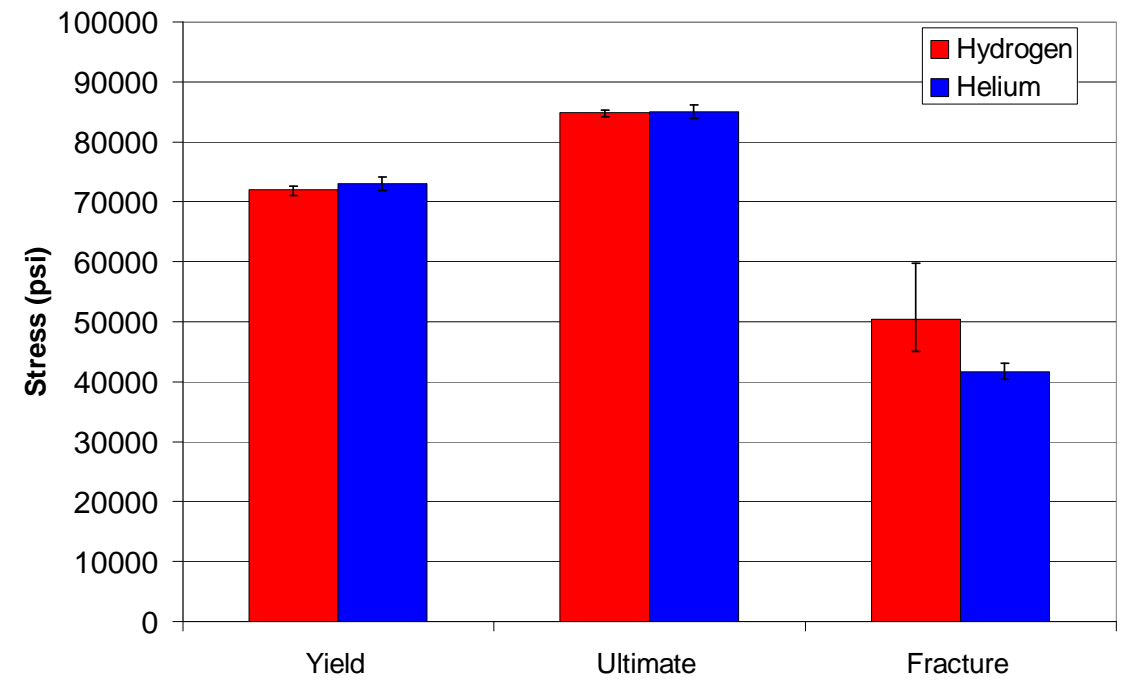

Fig. 34 - Illustration of yield strength, ultimate strength and fracture stress performance for Alloy B

From the results of this tensile testing, Alloys B and D were chosen for further evaluation in fracture and fatigue testing. 


\section{Fracture and Fatigue Testing Results}

Alloys B and D were selected for additional testing based on their tensile performance in gaseous hydrogen. Fracture and fatigue testing was carried out at Sandia National Laboratory in Livermore, CA at gaseous hydrogen pressures of $5.5 \mathrm{MPa}(800 \mathrm{psi})$ and $20.7 \mathrm{MPa}(3000 \mathrm{psi})$. All fracture measurements were performed according to ASTM E1820-09. Stable crack extension was observed in all cases and the fracture toughness was determined by constructing J-R curves for each test. The details of the testing method and fracture measurements in gaseous hydrogen are given in paper "Fracture and Fatigue of Commercial Grade API Pipeline Steels in Gaseous Hydrogen" "11.

The measured fracture toughness in gaseous hydrogen is greater for Alloy B than Alloy D, as shown in Figure 35.

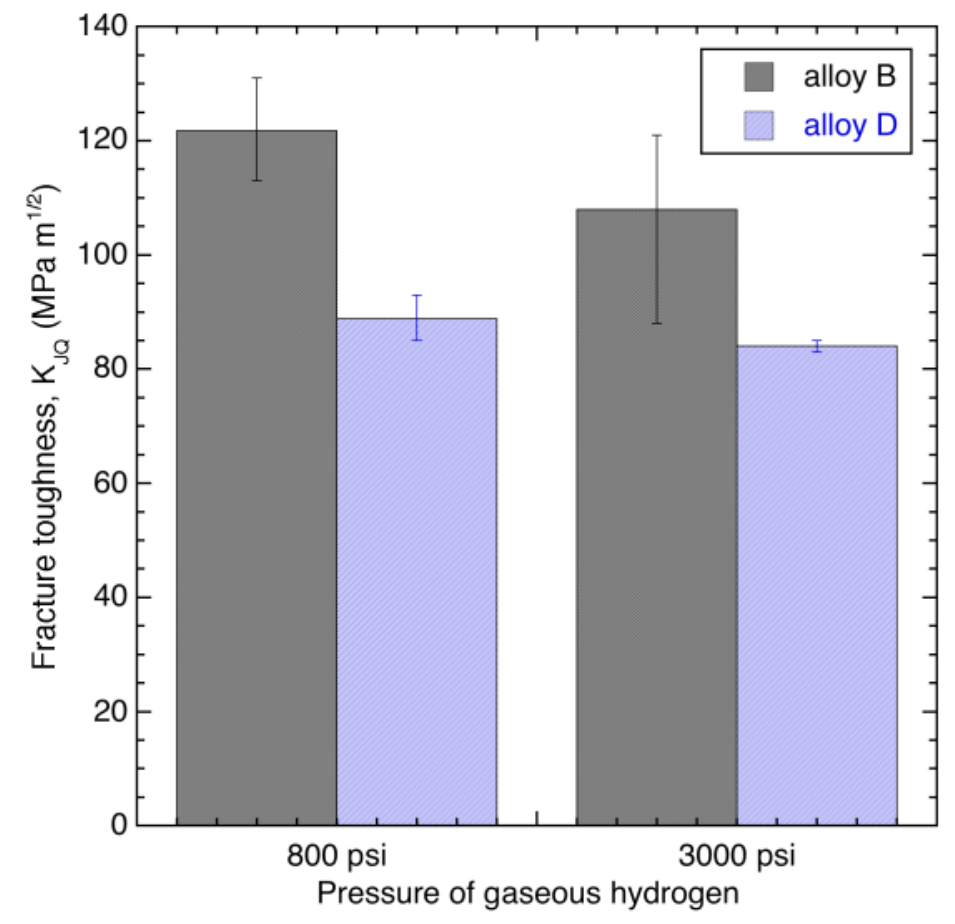

Fig. 35 - Fracture toughness measured in gaseous hydrogen. The error bars represent the minimum and maximum measured values (replicate specimens were measured for all conditions, except alloy $B$ at pressure of 3000 psi, for which three measurements were made)

These results do not follow the basic trend of decreasing fracture toughness for greater yield strength as Alloy B has higher strength than Alloy D, Figure 36. 


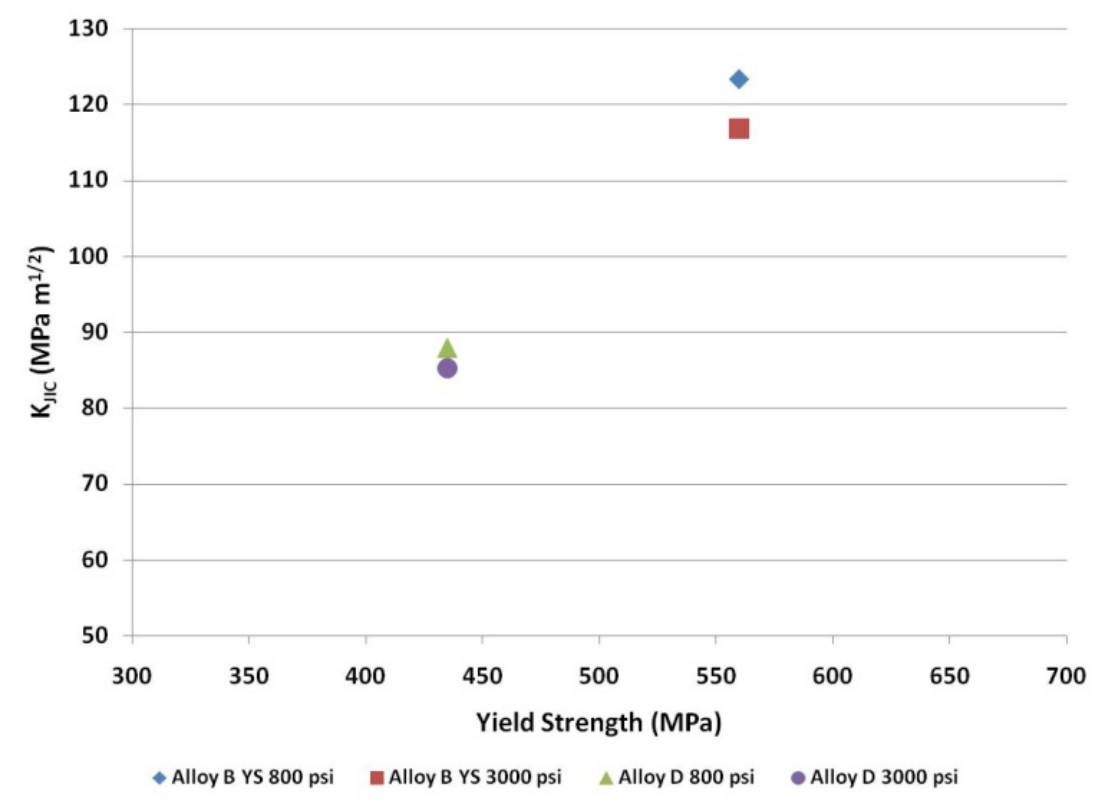

Fig. 36 - Strength vs. fracture toughness results for Alloys B and D

The strength difference between these alloys, however, is relatively small. Thus microstructural differences likely account for the difference of fracture resistance between these two alloys in gaseous hydrogen. In addition, the effect of pressure is relatively small: the fracture toughness decreases by 5-12\% for an almost four-fold increase of hydrogen pressure.

Even though both microstructures have reasonable fracture toughness, the ferrite $/ 10 \%$ coarse acicular ferrite microstructure of Alloy B performed better than that of $100 \%$ polygonal ferrite microstructure of Alloy D.

The fracture toughness of these alloys in air could not be measured with the given geometry (because the fracture toughness of the alloys is very large, which precluded crack growth in favor of global plastic deformation), which demonstrates that these alloys are strongly affected by exposure to gaseous hydrogen as observed in the tensile tests. Nevertheless, the critical stress intensity factor for crack advance (namely the fracture toughness) in gaseous hydrogen is unlikely to be exceeded for small cracks with modest ratio of length to crack depth. For example, consider a 10 -inch diameter pipe with a wall thickness of 0.3 in. operating in gaseous hydrogen pressure of $10.3 \mathrm{MPa}(1500 \mathrm{psi})$. The stress intensity factor associated with a through-wall crack (with length of twice the thickness) in the longitudinal direction will be less than $50 \mathrm{MPa} \mathrm{m}{ }^{1 / 2}$, which is significantly less than the fracture toughness that was measured in gaseous hydrogen.

Fatigue testing was also conducted at $5.5 \mathrm{MPa}(800 \mathrm{psi})$ and $20.7 \mathrm{MPa} 3000 \mathrm{psi}$ ) and a frequency of $1 \mathrm{~Hz}$. In addition, tests were performed at two R-ratios, 0.5 and 0.1 ( $\mathrm{R}$ is the ratio of the minimum to maximum load applied to the specimen). For a given set of test parameters, the fatigue crack growth rate (FCGR) in gaseous hydrogen is similar for both alloys, as shown in Figure 37. In general, the results of the fatigue testing show that the two alloys/microstructures perform approximately the same for values of R-ratio and pressure that were tested. 


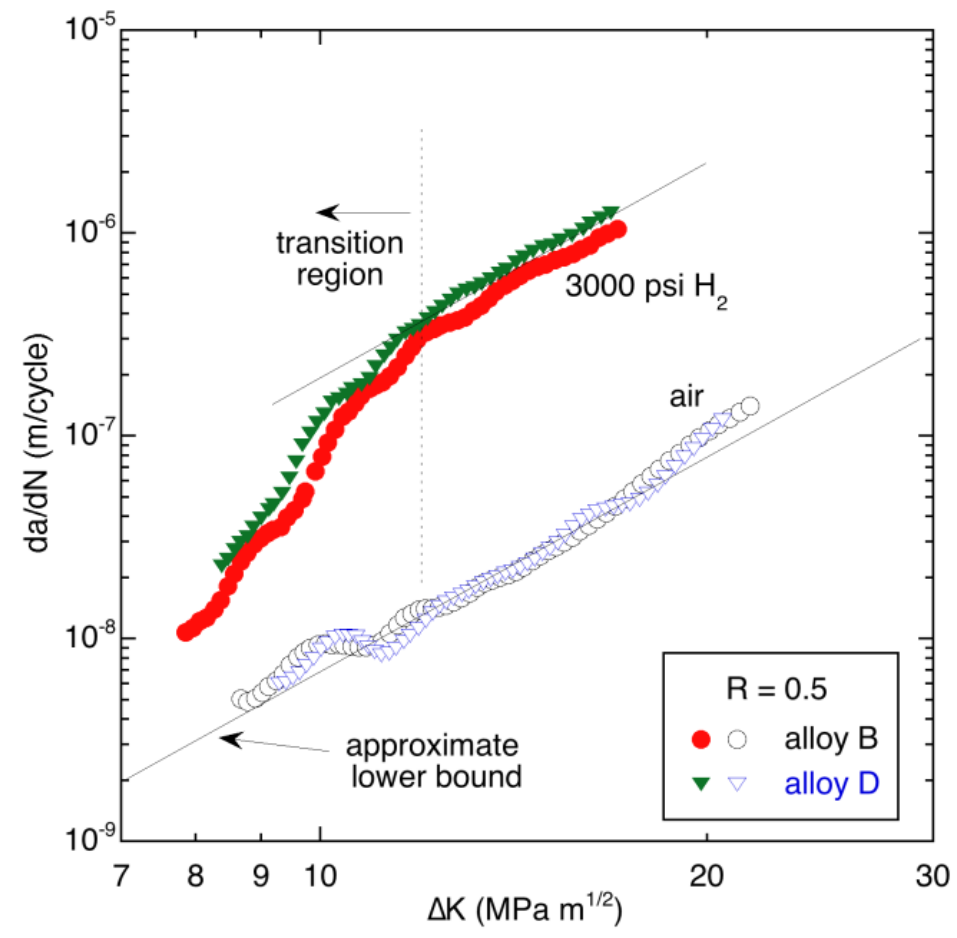

Figure 37: Fatigue crack growth of Alloy $B$ and Alloy D in gaseous hydrogen at pressure of 3000 psi, compared to fatigue in air

At relatively high $\Delta \mathrm{K}\left(>12 \mathrm{MPa} \mathrm{m}^{1 / 2}\right)$, the FCGR in gaseous hydrogen is about 20 times greater than in air. At lower $\Delta \mathrm{K}$, however, the FCGR in air and in gaseous hydrogen begin to converge, Figure 38. Presumably at values of $\Delta \mathrm{K}$ that are generally lower than measured in this study, the curves converge and the FCGR in gaseous hydrogen is the same as in air. However extrapolation to small values of $\Delta \mathrm{K}$ must be done with caution and consideration for the bounding FCGR in air.

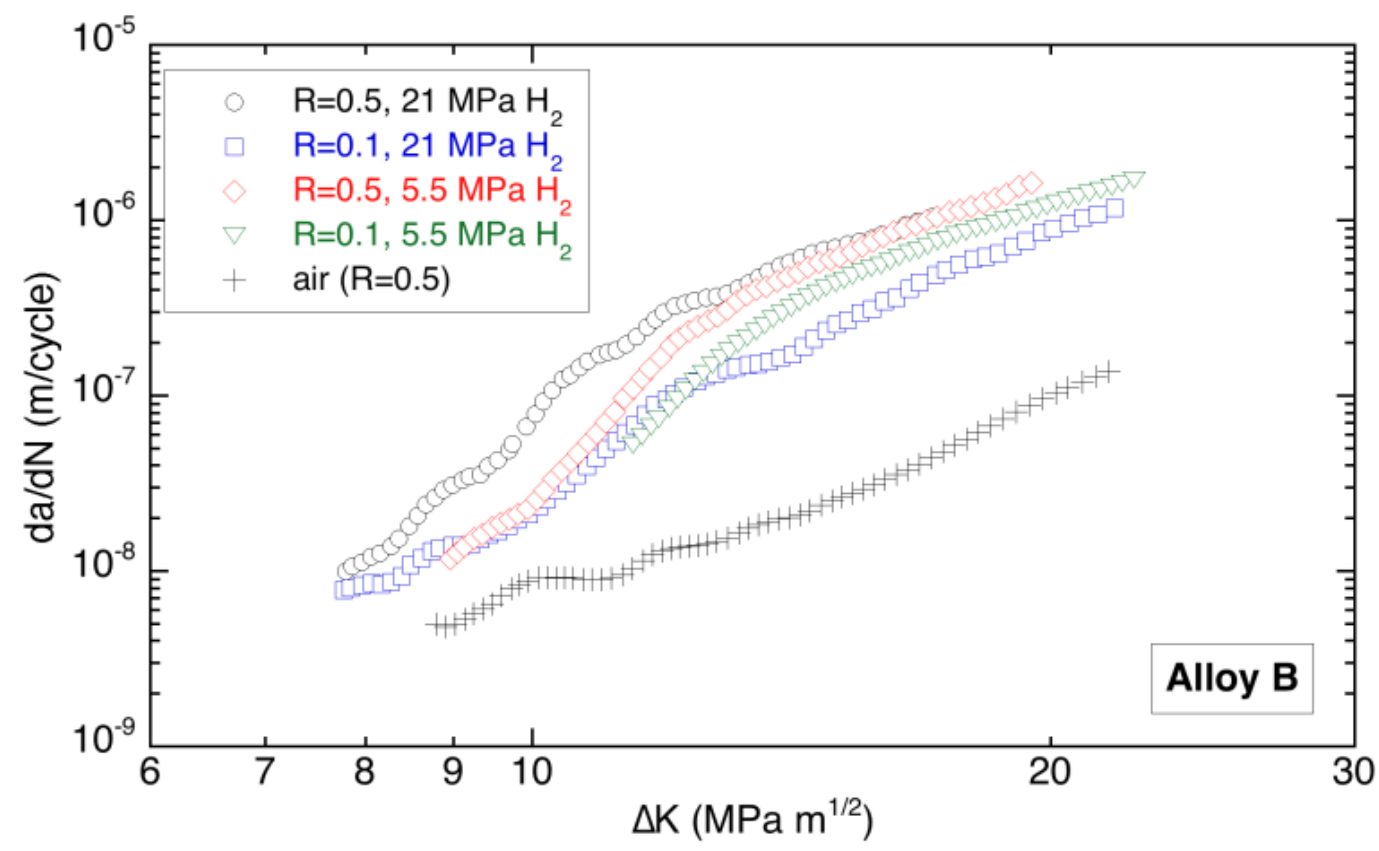




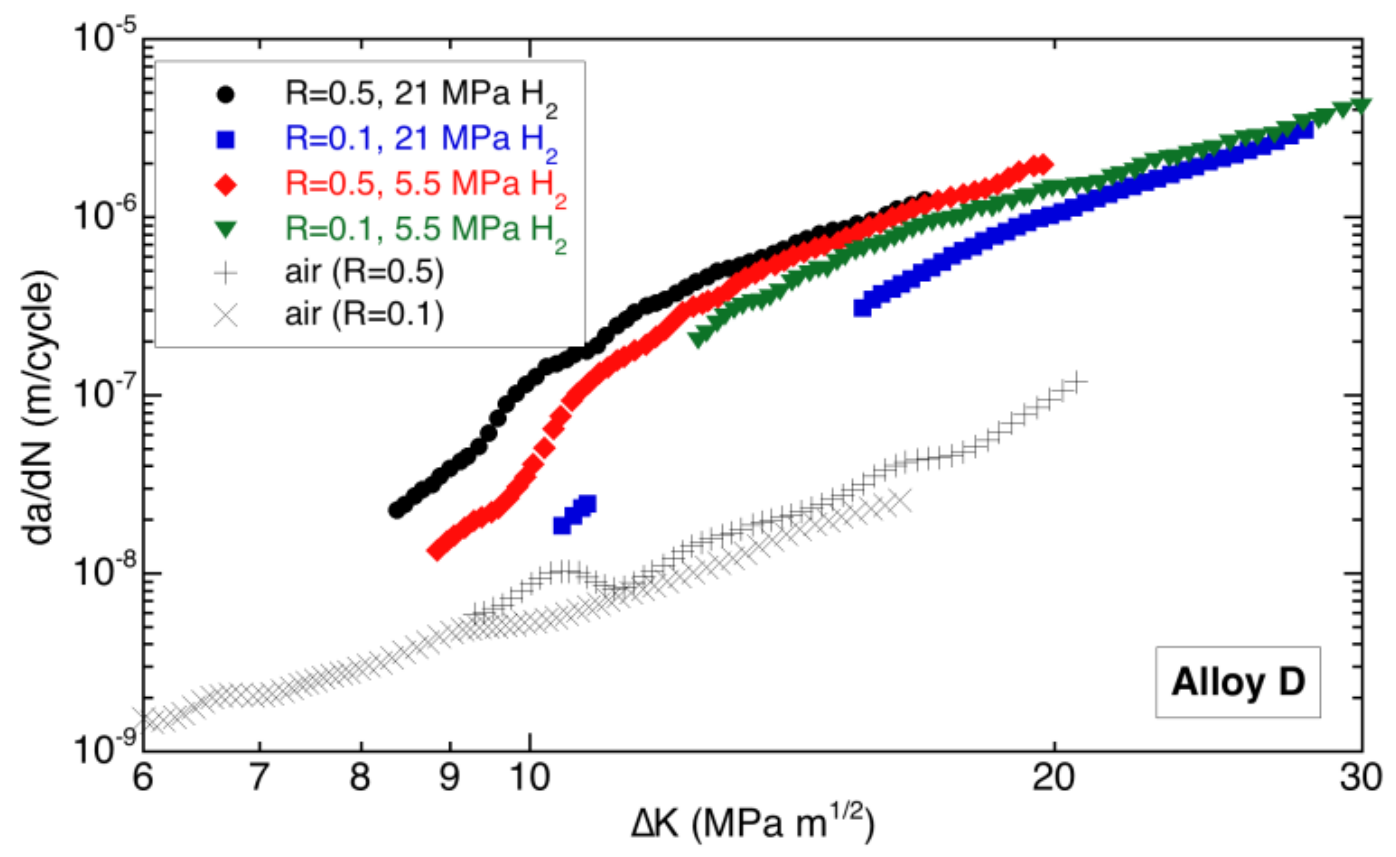

Fig. 38 - Measured fatigue crack growth rates for Alloy B and D

For example, extrapolating measured FCGRs to $\Delta \mathrm{K}<5 \mathrm{MPa} \mathrm{m}^{1 / 2}$ implies that the rate of crack growth is less in gaseous hydrogen than in air, which is unlikely. Near the FCGR threshold, however, there may be some differences between tests in gaseous hydrogen and in air as has been observed ${ }^{12}$. Testing at $\Delta \mathrm{K}<$ $7 \mathrm{MPa} \mathrm{m}{ }^{1 / 2}$ was not pursued in this study because of the length of the tests; a test at $1 \mathrm{~Hz}$ can require many days to complete (in constant load amplitude tests) when the crack growth rates are less than $10^{-8}$ $\mathrm{m} /$ cycle.

Figure 38 clearly shows a transition from high FCGRs in gaseous hydrogen at high $\Delta \mathrm{K}$ to FCGRs that are closer to those measured in air at relatively low $\Delta \mathrm{K}$. The transition region depends on R-ratio and pressure. For $\mathrm{R}=0.5$, this transition region occurs in the range of $\Delta \mathrm{K}$ between about 6 and $12 \mathrm{MPa} \mathrm{m}{ }^{1 / 2}$ independent of the pressure (at least within the pressure range of this study). For $\mathrm{R}=0.1$, the transition to lower FCGRs is shifted to greater values of $\Delta \mathrm{K}$. This is an effect of the greater absolute value of the stress intensity factor applied to specimen at higher values of $\mathrm{R}$ for the same value of $\Delta \mathrm{K}$ (e.g., for $\Delta \mathrm{K}=15$ $\mathrm{MPa} \mathrm{m}{ }^{1 / 2}, \mathrm{~K}_{\max }=30 \mathrm{MPa} \mathrm{m} \mathrm{m}^{1 / 2}$ for $\mathrm{R}=0.5$, and $\mathrm{K}_{\max }=16.7 \mathrm{MPa} \mathrm{m}^{1 / 2}$ for $\mathrm{R}=0.1$ ). The higher stress associated with the higher stress intensity factor will facilitate the effects of hydrogen. The measured FCGRs, however, converge for all the tested conditions at high values of $\Delta \mathrm{K}$, suggesting that the effect of stress saturates prior to reaching the critical stress intensity factor for rapid fracture.

The effect of pressure (at least for the range explored in this study) appears to be modest for $\Delta \mathrm{K}$ less than about $6 \mathrm{MPa} \mathrm{m}^{1 / 2}$ (based on extrapolation) and $\Delta \mathrm{K}$ greater than about $20 \mathrm{MPa} \mathrm{m}^{1 / 2}$; i.e., the effect of pressure is nominally bounded by the FCGR in air at low $\Delta \mathrm{K}$ and the limiting FCGR at large $\Delta \mathrm{K}$. In the transition region between the air bound and the high limit in gaseous hydrogen, FCGRs are generally lower at the lower pressure, particularly for $\mathrm{R}=0.1$. This is expected since the effects of hydrogen are enhanced as pressure is increased.

The FCGRs in the transition region are arguably the most important for systems that experience significant numbers of pressurization cycles. The high $\Delta \mathrm{K}$ region is not of particular interest because FCGRs greater than about $10^{-6} \mathrm{~m} /$ cycle are sufficiently rapid that cracks can extend millimeters in 
hundreds of cycles (and accelerating for a given pressure cycle). Crack-like defects in real pressurized structures (as often assumed in pipelines and pressure vessels) can induce significantly large stress intensity factors at the defects: $\mathrm{K}_{\max }$ of $10 \mathrm{MPa} \mathrm{m}{ }^{1 / 2}$ is relevant for defects near the detection limit in structures operating at a large fraction of the nominal yield stress of the material. Therefore, understanding the transition between FCGRs that are similar to air and those that are 20 times greater is important and necessary.

\section{Technical Accomplishment}

The project successfully demonstrated that steel microstructures do a play a role in the mechanical performance of various pipeline steels when exposed to gaseous hydrogen in pressures in the range of 800 to 3000 psi.

Screening techniques such as NACE TM0284 and tensile testing in the presence of hydrogen can be used to determine a given steels microstructure overall performance in the presences of gaseous hydrogen.

Fracture toughness is a critical path to microstructure design for gaseous hydrogen service up to $3000 \mathrm{psi}$ pressure. Fatigue performance plays a lesser role in this regard at the pressure ranges studied.

Pipelines with a minimum designed yield strength up to API X70 can potentially be used in hydrogen service as long as the appropriate microstructure of polygonal ferrite/acicular ferrite can be developed through alloy and process design.

\section{Technology Transfers}

During the entire project as data was being generated along with the additional information generated in the non-DOE funded "Phase 2" program, the testing parameters and results have been shared with various organizations/team members. Presentations have been made at each US DOE Annual Peer Review Meeting, at each DOE Pipeline Working Group meeting, paper/presentations at ASME PVP 2009, 2010, 2011 and the upcoming 2013 conferences, ASME International Pipeline Conferences in 2010 and 2012, 2008 and 2012 International Hydrogen Conference and with the ASME B31.12 Piping and Pipelines codes and standards committee. Project partner DGS Metallurgical Solutions, Inc. is a member of the ASME B31.12 codes and standards committee and is working with the committee to make guidance language modifications to the existing B31.12 code based on the results of the work from the original DOE funded project and additional "Phase 2" work. The ASME B31.12 committee has representation from three large industrial hydrogen producers which have access to the data generated by the initial program and the "Phase 2" program demonstrating the importance of proper microstructure selection in optimizing the design of hydrogen piping and pipeline systems.

\section{Publications and Presentations}

\section{Publications}

1. Stalheim, D., Govindarajan, M., “The Role of Continuous Cooling Transformation Diagrams for High Strength Oil and Gas Transmission Pipeline Steels" - Proceedings and Presentation at the $6^{\text {th }}$ ASME International Pipeline Conference, Calgary, Canada, September 2006. 
2. Hayden, L., Stalheim, D., “Metallurgical Considerations for Commercial Steels used for Hydrogen Service” - Proceedings and Presentation at Hydrogen08 Conference, Jackson Hole, WY USA September 2008.

3. Govindarajan, M., et.al., "Effect of Microstructure on Hydrogen Embrittlement Characteristics of Selected Pipeline Steels" - Presented at Hydrogen08 Conference, Jackson Hole, WY USA September 2008.

4. Hayden, L., Stalheim, D., “ASME B31.12 Hydrogen Piping and Pipeline Code Design Rules and their Interaction with Pipeline Materials Concerns, Issues and Research" - Proceedings of PVP2009, 2009 ASME Pressure Vessels and Piping Division Conference, Prague, Czech Republic, July 2009.

5. San Marchi, C., et.al., "Fracture and Fatigue of Commercial Grade API Pipeline Steels in Gaseous Hydrogen”, Presentation and Proceedings of the ASME 2010 Pressure Vessels \& Piping Division / K-PVP Conference, Bellevue, WA USA, July 2010.

6. Stalheim, D., et.al., "Microstructure and Mechanical Property Performance of Commercial Grade API Pipeline Steels in High Pressure Gaseous Hydrogen”, Proceedings and Presentation at the $8^{\text {th }}$ ASME International Pipeline Conference, Calgary, Canada, September 2010.

7. San Marchi, C., et.al., "Fracture Toughness and Fatigue Crack Growth of X80 Pipeline Steel in Gaseous Hydrogen”, Proceedings of the ASME 2011 Pressure Vessels \& Piping Division / KPVP Conference, Baltimore, MD, USA, July 2011.

8. Stalheim, D., et.al., "Continued Microstructure and Mechanical Property Performance of Commercial Grade API Pipeline Steels in High Pressure Gaseous Hydrogen”, Proceedings and Presentation at the $9^{\text {th }}$ ASME International Pipeline Conference, Calgary, Canada, September 2012.

9. Stalheim, D., et.al., “Microstructure and Mechanical Property Performance Evaluation of Commercial Grade API Pipeline Steels in High Pressure Gaseous Hydrogen”, 2012 International Hydrogen Conference- Hydrogen - Materials Interactions, Jackson Hole, Wyoming, USA, September 2012.

\section{Presentations}

1. “Materials Solutions for Hydrogen Delivery in Pipelines" - Summary of US Department of Energy Funded Research and Development Effort of Hydrogen Fuel Cells and Infrastructure Technologies Program, US Department of Energy Workshop, Augusta, GA USA, August 2005.

2. “On the Development of Fracture Criteria for Hydrogen Embrittlement of Pipeline Steels" Discussion on Fracture Mechanics in Hydrogen Embrittlement of API Pipeline Steel. A collaboration with the University of Illinois, Sandia National Laboratories, and Oak Ridge National Laboratories. Presented at ASTM TF G.01.06.08 Hydrogen Gas Embrittlement Workshop, Dallas, Texas USA, November 2005.

3. “Materials Solutions for Hydrogen Delivery in Pipelines" - Summary of US Department of Energy Funded Research and Development Effort of Hydrogen Fuel Cells and Infrastructure Technologies Program, Arlington VA USA, May 2006.

4. "Material Challenges in the Use of High Strength Steel Pipelines for High Pressure Hydrogen Gas Transmission" $-2^{\text {nd }}$ Hydrogen Panel Forum "Hydrogen Pipeline Transmission: Updates and Opportunities", $6^{\text {th }}$ ASME International Pipeline Conference, Calgary, Canada, September 2006.

5. “Materials Solutions for Hydrogen Delivery in Pipelines" - Department of Energy Pipeline Working Group for Hydrogen Delivery, Sandia National Laboratory, Livermore, CA USA, February 2008.

6. “Materials Solutions for Hydrogen Delivery in Pipelines-Peer Review" - Department of Energy Peer Review Meeting for Hydrogen Delivery, Arlington, VA USA, June 2008. 
7. “Materials Solutions for Hydrogen Delivery in Pipelines - Update" - Department of Energy Pipeline Working Group for Hydrogen Delivery, Jackson Hole WY USA, September 2008.

8. “Alloy/Processing/Microstructure Designs for High Strength Transmission Pipeline Steels” Department of Energy Pipeline Working Group for Hydrogen Delivery, Jackson Hole WY USA, September 2008.

9. "Materials Solutions for Hydrogen Delivery in Pipelines-Peer Review" - Department of Energy Peer Review Meeting for Hydrogen Delivery, Arlington, VA USA, May 2009.

10. “Materials Solutions for Hydrogen Delivery in Pipelines - Update” - Department of Energy Pipeline Working Group for Hydrogen Delivery, NIST Boulder, CO USA, August 2009.

11. "Materials Solutions for Hydrogen Delivery in Pipelines-Peer Review" - Department of Energy Peer Review Meeting for Hydrogen Delivery, Washington, DC USA, June 2010.

12. “Materials Solutions for Hydrogen Delivery in Pipelines-Peer Review" - Department of Energy Peer Review Meeting for Hydrogen Delivery, Arlington, VA USA, May 2011.

\section{Summary, Conclusions and Recommendations}

This originally funded DOE work coupled with the additional Phase 2 work has significantly increased the understanding of the role of steel alloy designs, microstructures and mechanical property performance when exposed to gaseous hydrogen in the pressure ranges of $800-3000$ psi. Even though there is mechanical property degradation with initial exposure to hydrogen for all steels evaluated, mechanical property performance of certain microstructures can become stable with increasing hydrogen pressure. Mechanical property performance of certain microstructures may be more than adequate to perform safely for hydrogen gas service applications. This strongly implies that pipeline steels that exist in some of the current North American transmission pipeline infrastructure may be suitable for gaseous hydrogen transportation. It also strongly suggests that current pipeline steel technology can be used to develop microstructures that have suitable mechanical properties in the presence of gaseous hydrogen in pressures up to 3000 psi.

From this original DOE funded work the following conclusions can be made:

1. Pipeline steel microstructures evaluated in the project all experienced an initial degradation in mechanical properties with initial exposure to hydrogen gas under pressure (800 psi) as measured by reduction in area tensile testing.

2. However, once the initial degradation was reached, microstructures behaved differently with continued increasing hydrogen pressure up to 3000 psi.

3. Microstructures of polygonal ferrite and/or acicular ferrite with no presence of upper bainite or pearlite performed the best in hydrogen pressures up to 3000 psi as measured by reduction in area tensile testing.

4. Absolute yield and ultimate strength were not affected by exposure to hydrogen; only the stress to final fracture was affected by hydrogen.

5. Fracture toughness varied by microstructure with slight decreases in toughness with increasing hydrogen pressure for each of the two microstructures tested.

6. Fatigue testing between the two microstructures with two different frequencies and pressures showed no significant difference when exposed to hydrogen.

7. Since fatigue was not significant between the two microstructures then microstructure design to optimize fracture toughness can be considered. A polygonal ferrite/acicular ferrite microstructure generated the highest fracture toughness values up to $3000 \mathrm{psi}$ of the two microstructures evaluated. 
8. Increasing yield strength did not affect the fracture toughness performance in hydrogen up to $3000 \mathrm{psi}$ as has been reported previously by others.

9. Even though the polygonal ferrite/acicular ferrite microstructure performed the best in this evaluation, this does not necessarily mean that some of the other microstructures are not suitable for hydrogen service. Suitability will have to be determined by the requirements of the piping/pipeline system transporting the hydrogen.

Based on the project work, the following recommendations can be made:

1. Correlations need to be developed between the fracture toughness/fatigue test results with those of a more traditional steel testing technique such as the V-notch Charpy toughness testing. The standard steel testing protocol then can be used in developing specifications.

2. Additional steel microstructures have been evaluated for fracture toughness since this original project, however, as illustrated in Figure 9 there are still additional alloys/microstructures and probably a few more added to the matrix (X70 induction bend pipe as an example) that should be evaluated.

3. Fatigue testing needs to be completed as illustrated in the Figure 9 matrix.

4. Various seam and girth welds need to be evaluated at 800 and 3000 psi. This includes submerged arc welded material along with other field welding techniques and consumable combinations.

5. Based on this work along with the additional work done in Phase 2, a clearer picture is developing of what an optimum metallurgical/alloy/microstructure hydrogen transmission pipeline may look like. A small (30-35 pipe lengths of a standard 40 feet length) rectangular demonstration pipeline should be built complete with a compressor station and monitoring equipment based on current knowledge and understanding. This line could be built and monitored at a national laboratory site such as Sandia National Laboratory - Livermore.

\section{Acknowledgements}

The research at Oak Ridge National Laboratory was sponsored by the U. S. Department of Energy, Office of Hydrogen, Fuel Cells and Infrastructure Technologies, under contract No. DE-AC05-00OR22725 with UT-Battelle, LLC.

The research at Sandia National Laboratory was partially sponsored by CBMM/Reference Metals Company, through a work for others agreement 082090204 with Secat, Inc. Sandia is a multi-program laboratory operated by Sandia Corporation, a Lockheed Martin Company, for the United States Department of Energy under contract DE-AC04-94AL85000.

The project team also wants to acknowledge the support of DOE Technology Development Manager Monterey Gardiner and DOE Project Officer Paul Bakke and contributions by personnel at Oak Ridge National Laboratory, Sandia National Laboratory and the University of Illinois - Urbana-Champaign.

\section{References}

1. Das, S., "Materials Solutions for Hydrogen Delivery in Pipelines", 2006 DOE Hydrogen Project Review, Arlington, VA, USA, May 2006. 
2. Das, S., "Materials Solutions for Hydrogen Delivery in Pipelines", 2006 DOE Pipeline Working Group Meeting, Lexington, KY, USA, September 2006.

3. Das, S., "Materials Solutions for Hydrogen Delivery in Pipelines", 2008 DOE Hydrogen Project Annual Report, September 2008.

4. Boggess, T., Stalheim, D., "Materials Solutions for Hydrogen Delivery in Pipelines", 2009 DOE Hydrogen Project Annual Report, July 2009.

5. Boggess, T., Stalheim, D., "Materials Solutions for Hydrogen Delivery in Pipelines", 2010 DOE Hydrogen Project Annual Report, July 2010.

6. D. Stalheim, L. Hayden, "Metallurgical Considerations for Commercial Steels used for Hydrogen Service", Proceedings of 2008 International Hydrogen Conference, Jackson Hole, WY USA, ASM International, p.332-340, 2009

7. L. Hayden, D. Stalheim, "ASME B31.12 Hydrogen Piping and Pipeline Code Design Rules and their Interaction with Pipeline Materials Concerns, Issues and Research", Proceedings of ASME PVP 2009 Conference, Prague, Czech Republic, July 2009.

8. ANSI/NACE Standard TM0284-2003, Item No. 21215, "Standard Test Method - Evaluation of Pipeline and Pressure Vessel Steels for Resistance to Hydrogen Induced Cracking", Revision January 17, 2003.

9. Secat, Inc., D. Stalheim, "Materials Solutions for Hydrogen Delivery in Pipelines", Presentation to DOE Pipeline Working Group, Sandia National Laboratory, Livermore CA, February 2008.

10. Secat, Inc., S. Ningileri, "Materials Solutions for Hydrogen Delivery in Pipelines", Presentation to DOE Pipeline Working Group, NIST National Laboratory, Boulder CO, August 2009.

11. C. San Marchi, B.P. Somerday, K.A. Nibur, D.G. Stalheim, T. Boggess and S. Jansto, "Fracture and Fatigue of Commercial Grade Pipeline Steels in Gaseous Hydrogen", (PVP2010-25825), Proceedings of PVP-2010, ASME Pressure Vessels and Piping Division Conference, Bellevue WA, July 2010.

12. S. Suresh, R. Ritchie, "Mechanistic Dissimilarities between Environmentally influenced Fatiguecrack Propagation at Near-threshold and Higher Growth Rates in Lower Strength Steels", Metal Science 16, p. 529-538, 1982. 